\title{
Efeitos da Exploração Madeireira de Baixo Impacto sobre uma Comunidade de Aves de Sub-bosque na Floresta Nacional do Tapajós, Pará, Brasil
}

\author{
Luiza Magalli Pinto HENRIQUES ${ }^{1}$, Joseph M. WUNDERLE JR. ${ }^{2}$, David C. OREN${ }^{3}$, Michael R. WILLIG ${ }^{4}$
}

\begin{abstract}
RESUMO
Este estudo compara a resposta de uma comunidade aves à exploração madeireira de baixo impacto através da distribuição das espécies em floresta controle e manejada ao longo de cinco anos com amostragem pré e pós-exploração. O procedimento de ordenação mostrou que a similaridade da comunidade de aves após a exploração madeireira foi menor que a similaridade entre as amostras do período de pré-exploração. Além disso, a ordem das abundâncias das 43 espécies mais comuns foi alterada entre o período anterior à exploração e 3 a 4 anos após a exploração na floresta manejada. A exploração afetou as taxas de captura de 20 espécies, diretamente ou através de uma interação com o tempo. Os insetívoros terrícolas e os insetívoros que seguem bandos mistos foram as guildas mais afetadas pela exploração madeireira. Ambas as guildas mostraram declínio, correlacionado com o tempo, em suas abundâncias em floresta manejada. Insetívoros seguidores de formigas e insetívoros arborícolas não apresentaram diferenças entre a floresta manejada e controle, apesar de algumas espécies dessas guildas terem apresentado efeitos relacionados ao manejo florestal, diretamente ou através de uma interação entre o tempo e o manejo. Frugívoros também não apresentaram efeitos significativos relacionados ao manejo florestal. Nectarívoros aumentaram tanto na floresta explorada como na floresta controle. Efeitos temporais de aumento ou declínio observados em guildas e em 12 espécies ocorreram tanto na floresta controle como na floresta explorada. Este resultado sugere que mudanças temporais na área explorada podem estar relacionadas à sucessão enquanto que mudanças temporais na floresta controle podem estar relacionados à exploração com intensidade de $40 \mathrm{~m}^{3} /$ ha de parcelas adjacentes.
\end{abstract}

PALAVRAS-CHAVE: Avifauna, Perturbação, Conservação, Manejo florestal, Floresta amazônica.

\section{Effects of low impact selective logging on an understory bird community in the Tapajós National Forest, Pará, Brazil}

\begin{abstract}
This study compares the avian response to low impact selective logging by comparing bird species distribution in control and cut forest during five years, with before and post-harvest samples. Ordination analysis showed that the similarity of the bird community post-harvest was lesser than the similarity of samples before harvest. Moreover, the order of abundances of the 43 most common species changed between before and 3 to 4 years post-harvest in the logged forest. Logging affected capture rates for 20 species, either directly or with an interaction with time. The terrestrial insectivorous and mixed-species flocks were the guilds most affected by logging. Both guilds showed decline, correlated with time, in abundances in cut forest. Obligate army ant followers and arboreal insectivorous did not show differences between cut and control forest, but some species in these guilds showed logging effects, either directly or with an interaction between time and logging. Frugivores also did not show logging effects. Nectarivores increased in both the cut forest and in the control forest. Temporal effects of increase or decline occurred in guilds and in 12 species occurring in the cut and control forest. This result suggests that temporal changes in the cut forest may have resulted from succession and temporal changes in the control forest may have resulted from nearby harvest with $40 \mathrm{~m}^{3} /$ ha intensity in adjacent forest blocks.
\end{abstract}

KEYWORDS: Avifaunal, Disturbance, Conservation, Tropical forest management, Amazon forest.

1 Instituto Nacional de Pesquisas da Amazônia, Diretoria, Assessoria de Relações Institucionais. Avenida André Araújo, 1756 Aleixo. CEP 69060-000. Manaus, AM - Brasil Caixa-Postal: 478. e-mail: magalli@inpa.gov.br

2 International Institute of Tropical Forestry, USDA Forest Service, P.0. Box 490, Palmer, Puerto Rico, 00721, USA

${ }_{3}^{3}$ Museu Paraense Emílio Goeldi, C.P. 399, 66017-970, Belém, Pará, Brasil

${ }^{4}$ Department of Biological Science, Texas Tech Univesity. Lubbock, Texas 


\section{INTRODUÇÃO}

Nos últimos anos, a exploração madeireira tem se expandido na Amazônia, onde a extração anual é de aproximadamente sete milhôes de árvores, com valor de 2,5 bilhōes de dólares (Laurance, 1998; Lentini et al., 2003). Aproximadamente $80 \%$ de toda essa exploração é ilegal e realizada sem qualquer tipo de manejo florestal (Laurance, 1998). Os impactos dessa atividade não têm sido muito bem documentados nas imagens de satélite. Entretanto, o recente aumento da exploração madeireira na Amazônia certamente tem contribuído para um acentuado aumento da degradação florestal e da probabilidade de fogo (Uhl \& Buschbacher, 1985; Uhl \& Kauffman, 1990). Contudo, manejo florestal de produtos madeireiros pode representar uma das poucas atividades economicamente viáveis que poderiam manter biodiversidade sobre áreas extensas (Frumhoff, 1995; Chazdon, 1998; Whitman et al., 1998). A recente designação de $500.000 \mathrm{~km}^{2}$ de florestas nacionais indica que métodos que minimizam impactos serão rapidamente implementados ao longo da Amazônia (Veríssimo et al., 2002a; 2002b). Nesses sistemas, as clareiras abertas na exploração madeireira simulariam os diâmetros típicos de clareiras naturais pela queda de árvores, as quais são os principais sítios de regeneração natural das florestas tropicais (Hartshorn, 1989).

Os efeitos econômicos e silviculturais da exploração madeireira têm sido relativamente bem estudados em florestas tropicais (Whitmore, 1997). Contudo, somente recentemente estes estudos têm examinado os efeitos sobre animais (Frumhoff, 1995; Mason \& Thiollay, 2001).

As aves talvez sejam o grupo mais amplamente estudado em relação aos efeitos da exploração madeireira na região Neotropical, especialmente na Amazônia (Johns, 1991; Thiollay, 1992; Mason, 1996; Whitman et al., 1998; Guilherme \& Cintra, 2001; Mason \& Thiollay, 2001; Woltmann, 2003). Contudo, generalizações sobre os efeitos de exploração madeireira sobre as comunidades de aves são relativamente limitadas devido a deficiências no desenho experimental destes estudos (Whitmam et al., 1998). Por exemplo, alguns estudos falharam ao não verificarem a similaridade entre os sítios controle e sítios de tratamento antes e depois da exploração. Em outros, as amostragens das aves eram restritas as áreas mais afetadas pela exploração (por exemplo, ramais de arraste e clareiras abertas pela exploração) e ignorada a matriz florestal circundante, onde a comunidade de aves poderia ter sido menos afetada. Finalmente, nenhum estudo tem seguido o efeito da exploração por um período de tempo longo.

A despeito das dificuldades de comparações entre os vários estudos sobre os efeitos da exploração madeireira sobre as comunidades de aves, alguns padróes gerais de resposta começam a aparecer (e.g., Mason \& Thiollay, 2001).
A extensão e a intensidade da exploração madeireira e a quantidade de tempo após a exploração são os fatores mais relevantes para se entender os efeitos diretos da retirada de madeira sobre comunidades de aves. Não é surpreendente que a maior quantidade de madeira explorada em um sítio implique em uma maior mudança estrutural da floresta e correspondentemente a um maior impacto sobre as comunidades animais (e.g., Johns, 1991; Mason, 1996). Nos primeiros anos após a exploração, a estrutura da vegetação em sítios explorados é inversa a da floresta original, ou seja, essas áreas apresentam um grande crescimento secundário nos estratos mais baixos e um dossel aberto. Estas mudanças na estrutura florestal persistem por um tempo considerável e têm grande efeito sobre as comunidades animais, principalmente devido mudanças no microclima, nas fontes alimentares, no substrato de forrageamento e na vulnerabilidade a predadores (Mason \& Thiollay, 2001).

Espécies de aves do interior da floresta, especialmente as do sub-bosque ou insetívoros terrícolas, são as espécies mais vulneráveis aos efeitos da exploração madeireira. Esta também é a guilda mais negativamente afetada pela fragmentação florestal na Amazônia Central (Stouffer \& Bierregaard, 1995a). Após a exploração madeireira, declínio das populaçōes de aves também pode ser causado pela perda de requerimentos ecológicos das espécies, por exemplo, cavidades em árvores grandes para nidificação ou dependência de frutos de espécies vulneráveis à exploração (Mason \& Thiollay, 2001). Por outro lado, algumas espécies de aves aumentam suas populaçôes nos hábitats secundários resultantes da abertura de dossel, o que é evidente em algumas aves nectarívoras, frugívoras e insetívoras de borda de floresta e de clareiras (Thiollay, 1992; 1997).

Este estudo analisa os impactos da exploração madeireira de baixo impacto sobre as aves de sub-bosque. Essas aves são particularmente vulneráveis a abertura do dossel florestal (Karr, 1982; Wong, 1985; Johns, 1991; Thiollay, 1992; 1997; Stouffer \& Bierregaard, 1995a, b; Mason \& Thiollay, 2001) e são potencialmente as mais afetadas pela exploração da madeira, pois a estrutura e o microclima deste microhábitat, caracterizado pela baixa luminosidade e alta umidade, são fortemente alterados pela exploração madeireira. Este estudo difere dos anteriores por comparar populaçóes de aves antes e depois da exploração madeireira de baixo impacto em sítios localizados em áreas exploradas e controle. A resposta temporal da comunidade de aves no período pós-exploração foi acompanhada ao longo quatro anos, quando o crescimento secundário da vegetação nas áreas exploradas é mais intenso. Especificamente é investigado: 1) como a comunidade de aves difere em relação à composição de espécies e abundância ao longo do tempo; 2) como e se a diversidade e riqueza de espécies são afetadas pela extração madeireira; 3) se 
existem grupos ecológicos que apresentam diferenças em sua vulnerabilidade à extração de madeira.

\section{MATERIAL E MÉTODOS}

\section{ÁREA DE ESTUDO}

A FLONA Tapajós $\left(20^{\circ} 45^{\prime} \mathrm{S} 55^{\circ} 00^{\prime} \mathrm{W}\right)$ é uma unidade do sistema de florestas nacionais administrado pelo Instituto Brasileiro de Meio Ambiente e Recursos Naturais Renováveis (IBAMA), criada pelo Decreto no. 73.684, de fevereiro de 1974. A FLONA Tapajós possui cerca de 560.000 ha e está localizada próxima a foz do rio Tapajós no oeste do Estado do Pará, abrangendo áreas dos municípios de Belterra, Aveiro, Rurópolis e Placas. É limitada geograficamente a oeste pelo rio Tapajós, a leste pela Rodovia Santarém-Cuiabá (BR-163) e ao sul pelo rio Cupari (Figura 1)

A altitude média é de $175 \mathrm{~m}$, o relevo é plano ou dissecado e o principal tipo de solo é classificado como do tipo Latossolo Amarelo Distrófico, textura muito argilosa. O clima da região é do tipo Ami, segundo a classificação de Köopen, com temperatura média anual de $25^{\circ} \mathrm{C}$ e umidade relativa de $86 \%$. A precipitação anual é de cerca de 1.920 $\mathrm{mm}$. O período de chuva mais intenso ocorre de dezembro a maio, apresentando uma curta estação seca, usualmente entre agosto e outubro, na qual a precipitação é menor que $60 \mathrm{~mm}$ (Parrotta et al., 1995).

Os estudos sobre a vegetação das florestas da região do rio Tapajós, incluindo a que ocorre na FLONA Tapajós, e o estado atual dos inventários botânicos para essa região foram apresentados em Daly \& Prance (1989). Estudos da estrutura florestal e florística são citados em Parrotta et al. (1995). Apesar de existirem vários tipos distintos de florestas úmidas dentro da FLONA Tapajós, este estudo foi conduzido somente em floresta densa de terra-firme caracterizada por espécies emergentes tais como Bertholletia excelsa, Couratari spp., Dinizia excelsa, Hymenaea coubaril, Manilkara huberi, Parkia spp., Pithecellobium spp. e Tabebuia serratiolia (Silva et al., 1985). A altura do dossel das florestas não perturbadas fica entre $30 \mathrm{~m}$ e $40 \mathrm{~m}$ podendo algumas árvores emergentes chegar até $50 \mathrm{~m}$. Os sítios de estudo estão localizados sobre platô em uma área virtualmente ausente de cursos d'água, com exceção de um pequeno igarapé de terra firme que corre ao sul dos sítios de estudo próximos ao quilômetro 83. A maior parte deste igarapé permanece no interior da floresta apresentando uma área mais aberta à beira da Rodovia Santarém-Cuiabá. Em relação a outros sítios de estudo na região neotropical, a área estudada possui uma baixa heterogeneidade de hábitats. Não há na área estudada vegetação florestal sazonalmente

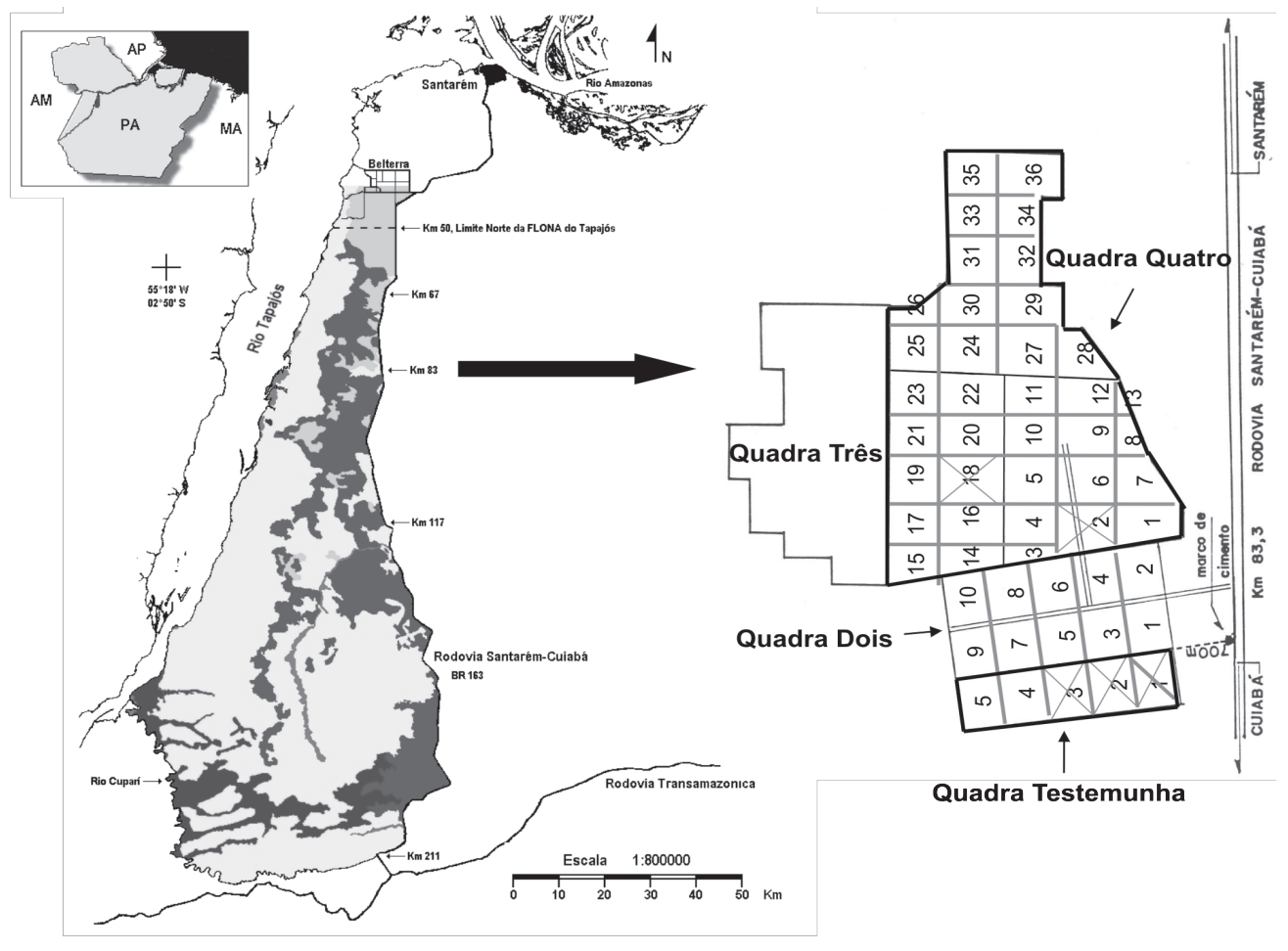

Figura 1 - Mapa de localização da FLONA Tapajós, Brasil (adaptado de Parrota et al. 1995) e das Quadras de Exploração e Testemunha (adaptado de Barros et al. 1996). As parcelas em que foram desenvolvidos estudos utilizando redes de neblina estão marcadas com um X. 
inundada (florestas de várzea ou igapó) ou abundância de bambu, que são hábitats que possuem um grande número de espécies especializadas (Remsen \& Parker, 1983; Kratter, 1997).

O estudo foi desenvolvido na grade de 5.000 ha $\left(3^{\circ}\right.$ 21'21" S, 54 56'58" W) estabelecida para demonstração de manejo florestal para retirada de madeira na FLONA Tapajós (Barros \& Jardim, 1996). Em 1997, 200 hectares de floresta primária sofreram exploração de baixo impacto, cujo objetivo é minimizar os danos colaterais à floresta através de um cuidadoso planejamento das atividades relacionadas com a exploração madeireira (inventário florestal de 100\% das árvores com DAP acima de $35 \mathrm{~cm}$, corte de cipó, escolha prévia das árvores exploradas, planejamento dos ramais e pátios, planejamento da queda das árvores, utilização de trator florestal e planejamento da sua entrada para minimizar danos e compactação do solo). A intensidade de exploração foi de aproximadamente $20 \mathrm{~m}^{3} / \mathrm{h}$ e as estradas e pátios de estocagem contribuíram para uma perda máxima de aproximadamente $5-7 \%$ da cobertura de copa em cada parcela. Em novembro de 1999, foi iniciada a exploração de 500 ha de floresta pela iniciativa privada. A intensidade da exploração foi aumentada para $40 \mathrm{~m}^{3} / \mathrm{ha}$ (cerca de seis árvores por hectare), o que está próximo à intensidade das exploraçōes comerciais praticadas fora da FLONA Tapajós. Em 2003, uma área de 3.200 ha já havia sido totalmente explorada utilizando essa mesma intensidade.

Os sítios de amostragem foram duas parcelas disjuntas (C-1 e C-3), localizadas na Quadra Testemunha, a qual é mantida como controle da exploração e dos tratamentos silviculturais planejados para a área, e duas parcelas manejadas disjuntas (B-18 e B-2), localizadas na Quadra 4 e exploradas através de manejo florestal de baixo impacto. Todas as parcelas possuem uma área de 100 ha (Figura 1).

Cada parcela controle está circundada por floresta de terra firme não perturbada em três lados (exceto a parcela C-1 que apresentava $25 \%$ de um dos lados composto por vegetação secundária de cerca de 30 a 40 anos). O quarto lado é adjacente a uma das quadras na qual ocorreu exploração madeireira (com intensidade aproximada de $40 \mathrm{~m}^{3} / \mathrm{ha}$ ) durante o período deste estudo. Ambas as parcelas controle eram atravessadas por um pequeno igarapé de terra firme. As duas parcelas manejadas eram limitadas por floresta não perturbada sobre um dos lados e floresta explorada (com intensidade aproximada de $40 \mathrm{~m}^{3} /$ ha) sobre os outros três lados durante o período deste estudo. As duas parcelas manejadas eram separadas por uma distância de cerca de $2,5 \mathrm{~km}$ e separadas das parcelas controle por uma distância de 2 a $4,5 \mathrm{~km}$.

A exploração madeireira nas duas parcelas manejadas foi iniciada em outubro de 1997 e finalizada em dezembro do mesmo ano. As duas parcelas manejadas foram exploradas para demonstração de manejo florestal de baixo impacto, que é caracterizado pela adoção de um conjunto de estratégias cujo objetivo é minimizar danos colaterais e compactação do solo (ver Johns et al., 1996; Barreto et al., 1998).

$\mathrm{Na}$ parcela B-2 a intensidade de exploração foi de $18,7 \mathrm{~m}^{3} / \mathrm{ha}$, resultando em um total de $1.870,49 \mathrm{~m}^{3}$ (volume geométrico) removido de uma área de 100 ha $(1.000 \mathrm{~m} \mathrm{x}$ $1.000 \mathrm{~m}$ ). A parcela B-18 foi explorada com uma intensidade de $18,73 \mathrm{~m}^{3} /$ ha, resultando em $1.872,708 \mathrm{~m}^{3}$ removidos de uma área de $100(1.200 \mathrm{~m} \times 800 \mathrm{~m})$.

\section{AMOSTRAGEM}

Redes de neblina (mist nets) foram usadas para amostrar as aves, pois permitem uma amostragem similar e simultânea de numerosos sítios e evitam as dificuldades de detecção e identificação de aves por observação visual ou auditiva. Uma outra vantagem é que este método focaliza aves de subbosque, que é o grupo de aves mais afetado pelas atividades de exploração madeireira (Mason \& Thiollay 2001). Contudo, redes de neblina não amostram a comunidade de aves de maneira aleatória e muitas espécies de aves são sub-representadas em amostras de redes de captura (Karr, 1981; Bierregaard, 1990a, 1990b, Remsen \& Good, 1996). Portanto, a taxa de captura não pode ser interpretada como um índice de abundância direto. Por esse motivo, tem sido recomendado que este método seja utilizado somente para comparar as taxas de captura das mesmas espécies ou grupos de espécies com comportamento similar (Karr, 1981; Bierregaard, 1990a, 1990b).

Os estudos foram iniciados com uma amostragem préexploração em setembro de 1997. Subseqüentemente, seis amostragens pós-exploração foram realizadas a partir de fevereiro de 1998. As quatro parcelas foram amostradas através de duas estaçôes de captura composta por seis linhas de redes paralelas armadas no centro de cada parcela. Cada linha de rede era separada por $200 \mathrm{~m}$ e continha cinco redes de $12 \mathrm{~m}$ x $2 \mathrm{~m}$ e malha de $36 \mathrm{~mm}$ por linha. As seis linhas de redes, ou seja, 30 redes, foram operadas simultaneamente por dois dias consecutivos das 6:00h até 15:00h, período no qual as redes eram checadas de hora em hora. Em seguida, as redes eram movidas para uma segunda estação de captura na mesma parcela e operadas por igual período. Portanto, cada parcela foi amostrada por um período de quatro dias utilizando 12 linhas de rede. Duas linhas de rede eram localizadas $30 \mathrm{~m}$ distantes do igarapé que cruzava as duas parcelas controle e cinco linhas de redes em C-1 ficaram localizadas em mata secundária. Os períodos de amostragem foram: agosto - setembro 1997, fevereiro - março 1998, novembro 1998, abril 1999; junho 1999; setembro 2000; novembro 2001.

As mesmas localizações das linhas de redes foram mantidas antes e após a exploração madeireira, portanto, as aves foram 
amostradas ao longo de um mosaico formado pela exploração. Em alguns casos as linhas de redes foram deslocadas alguns metros para evitar aberturas muito grandes que pudessem afetar as taxas de captura. Isto foi consistente com o objetivo do estudo que era identificar aves florestais sobrevivendo em áreas exploradas.

Todas as aves foram marcadas com anilhas de alumínio numeradas ou com anilhas plásticas coloridas, com exceção dos beija-flores. As penas da cauda ou da asa dos beija-flores eram cortadas para identificar as aves recapturadas em uma mesma sessão. Aves recapturadas dentro da mesma sessão não eram registradas, mas eram registradas entre sessôes. Todas as aves foram identificadas até espécie e sua idade e sexo determinados quando possível. Medidas morfométricas padronizadas para asa, cauda e tarso foram efetuadas quando um indivíduo era capturado pela primeira vez. Todas as aves foram pesadas e analisadas para evidências de atividade reprodutiva (placa de incubação) e muda.

\section{ANÁLISE}

As parcelas de 100 ha consistiram nas unidades de amostragem da comunidade de aves. Comparaçōes estatísticas entre as quatro parcelas foram realizadas utilizando as taxas de captura em 1.000 horas-rede como um índice de abundância, onde uma hora-rede (HR) significa $12 \mathrm{~m}$ de rede aberta por uma hora. As recapturas durante uma mesma sessão foram excluídas da análise e as recapturas entre sessōes foram incluídas. Foram considerados 5 anos de amostragem categorizados em: pré-exploração (tempo 0); 0-1 ano após a exploração (tempo 1); 1-2 anos após a exploração (tempo 2); 2-3 anos após a exploração (tempo 3); 3-4 anos após a exploração (tempo 4). Para os anos em que ocorreram duas sessōes de captura, foi utilizada a média das taxas de captura.

As análises foram desenvolvidas utilizando a taxa de captura de uma dada espécie em cada sítio, bem como para as guildas baseadas em sua classificação ecológica (Henriques et al., 2003). A classificação das guildas incluiu tanto uma classificação simples como uma categorização complexa das espécies. Guildas simples incluíram nectarívoros, frugívoros, insetívoros e onívoros. Guildas complexas incluíram uma subdivisão de algumas dessas guildas simples e incluíram seguidores de formigas, insetívoros solitários, insetívoros seguidores de bandos mistos, frugívoros solitários, frugívorosinsetívoros solitários, frugívoros-insetívoros seguidores de bandos mistos.

Para testar se as taxas de captura de uma dada espécie apresentavam diferenças entre as parcelas manejada e controle antes da exploração, foi utilizado o teste KruskalWallis, que é equivalente a ANOVA um critério, e então o teste qui-quadrado com correção de Yates para espécies com tamanho amostral suficiente $(n \geq 6$ capturas, teste exato de
Fisher). Também se comparou a ordem de distribuição das abundâncias através do teste Kolmogorov-Smirnov.

Para testar se as taxas de captura de uma dada espécie ou guilda apresentavam diferenças entre as parcelas manejadas e controle após a exploração, foi utilizado o teste de Wilcoxon e ANOVA fatorial. O primeiro é um teste não-paramétrico que compara observaçōes pareadas de uma amostra em ocasiōes distintas e é baseado no sentido e na magnitude das diferenças. Os pares de observaçóes foram as taxas de captura pré e pósexploração nas mesmas parcelas. A ANOVA fatorial testou o efeito do tempo ( 5 anos) e do manejo (parcelas controle vs. parcelas manejadas). Correlação de Spearman foi usada para avaliar a associação de taxas de captura (espécies e espécies combinadas em guildas) com o tempo. Todos os testes consideram um nível de significância de $\mathrm{P}<0.05$.

Com o objetivo de identificar padrōes no nível da comunidade, as amostras em redes de neblina também foram ordenadas através de uma análise de correspondência retificada (DCA - Detrended Correspondence Analysis). Essa análise utiliza a similaridade nas associações de espécies para ordenar os sítios e já foi utilizada para estudar comunidade de aves de sub-bosque em fragmentos florestais (Stouffer \& Bierregaard, 1995a). A análise foi realizada em duas matrizes. Uma composta por todas as espécies e a outra composta por todas as espécies com mais de 6 indivíduos capturados, para reduzir possíveis desvios causados pela presença de espécies raras.

\section{RESULTADOS}

\section{PADRÕES GERAIS NO NÍVEL DA COMUNIDADE}

Em $30.240 \mathrm{HR}$ em cinco anos foram registradas 4.641 capturas representando 132 espécies. A acumulação de espécies foi mais rápida nas primeiras 400 capturas, tanto na floresta controle como na floresta manejada (Figura 2). A curva acumulativa de espécies alcançou um platô em torno de 105 espécies na área controle e cerca de 90 espécies na área manejada. Entretanto, novas espécies continuaram sendo encontradas em uma razão constante, apesar de mais lenta, até o patamar de 118 espécies na área controle e 110 espécies na área manejada.

O procedimento jackknife envolvendo amostragem com replicação estima cerca de 138 espécies na floresta controle e 133 espécies na floresta manejada (Figura 2), indicando que uma amostra de 600 capturas deve apresentar cerca de 96 espécies na área manejada e 101 espécies na área controle.

A ordenação das amostras através de DCA mostrou uma substancial variação espacial e temporal nas amostras tanto das parcelas em floresta controle como em floresta manejada (Figura 3). O primeiro eixo, com um autovalor de 0.151 , separou as amostras da floresta controle e da floresta 
manejada demonstrando uma variação espacial relacionada com a presença de espécies raras, escores altos, e espécies características de hábitats secundários e hábitats criados por rios, escores baixos. O segundo eixo, com um autovalor de 0.072 , reunião as quatro amostras do período de préexploração.

\section{PRÉ-EXPLORAÇÃO}

Um total de 737 capturas de 82 espécies em 4.320HR representando $64 \%$ das espécies capturadas em redes e $24 \%$ das espécies registradas para a FLONA Tapajós foi registrado no período anterior a exploração madeireira (Apêndice). As parcelas localizadas na área de floresta manejada apresentaram um total de 311 capturas de 55 espécies em $2.160 \mathrm{HR}$ representando $42 \%$ das espécies capturadas em redes e $16 \%$ das espécies registradas para a FLONA Tapajós antes que a exploração madeireira fosse iniciada. Isto representa uma taxa de captura de 143.98 indivíduos/1.000HR. As parcelas localizadas na área de floresta controle apresentaram 426 capturas de 74 espécies no mesmo número de horasrede, representando uma taxa de captura de 197.22 indivíduos/1.000HR.

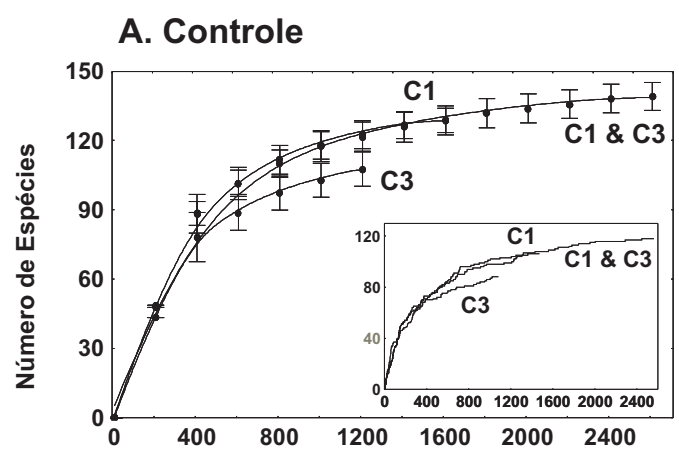

B. Manejada

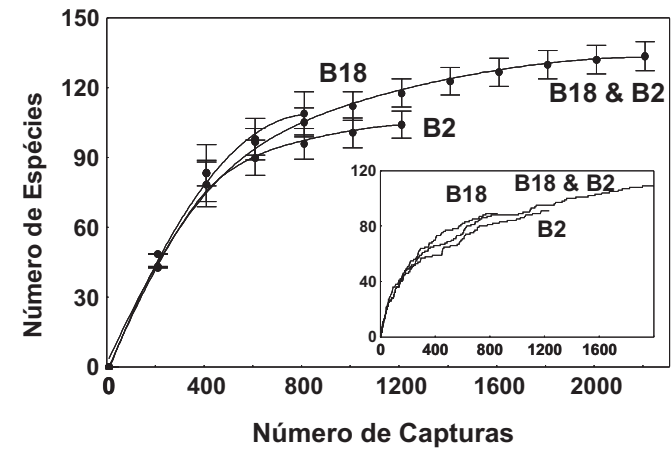

Figura 2 - Riqueza de espécies, em relação ao número acumulativo de indivíduos amostrados, estimada através do método jackknife, com reposição, para amostras em floresta controle (A - parcelas C1 e C3 da Quadra Testemunha) e em floresta manejada (B - parcelas B2 e B18 da Quadra 4) na FLONA Tapajós, Brasil. 0 gráfico inserido mostra a riqueza de espécies observada, em relação ao número acumulativo de indivíduos em redes de neblina, nos mesmos sítios. Barras representam 1 erro padrão.
Um número significativamente maior de indivíduos foi capturado na floresta controle comparado à floresta manejada, considerando uma distribuição com proporções esperadas iguais $\left(\chi^{2}=17.94, \mathrm{gl}=3, \mathrm{P}<0.001\right)$. As taxas de captura das espécies das parcelas localizadas na floresta controle não foram significativamente distintas das parcelas localizadas na floresta manejada antes da exploração $(H=6.36, \mathrm{gl}=3, \mathrm{P}=0.084)$. Contudo, tomando-se as parcelas duas a duas, a parcela B18 foi estatisticamente distinta da parcela C1 (Teste de KruskalWallis, $H=6.433$, $\mathrm{gl}=1, \mathrm{P}=0.01$ ).

A espécie mais capturada em ambas as parcelas manejadas, Glyphorynchus spirurus, apresentou $17.2 \%$ e $20.4 \%$ do total de capturas em B-18 e B-2, respectivamente. Outras 19 espécies apresentaram cinco ou mais capturas, representando mais de $79 \%$ do total de capturas do período de pré-exploração nas parcelas manejadas (Tabela 1). O restante das espécies foi distribuído ao longo de uma longa cauda de espécies raras. Do total de 55 espécies registradas nas parcelas manejadas, oito espécies não foram registradas nas parcelas controle no período de pré-exploração. Estas espécies foram registradas ao longo do estudo em todas as parcelas e permaneceram raras em redes de neblina, com a exceção de Pyriglena leuconota com uma taxa de captura 1.16 indivíduos/1.-000HR ao final do estudo ( $\mathrm{n}=35$ indivíduos).

Vinte e sete espécies foram registradas apenas nas parcelas da floresta controle (17 somente em C1, seis somente em C3 e quatro em ambas as parcelas), ou seja, o equivalente a quase $50 \%$ da riqueza registrada nas parcelas em floresta manejada durante o período de pré-exploração e aproximadamente $32 \%$ da riqueza em espécies das quatro parcelas combinadas. A maior parte dessas espécies, 19 no total, foram registradas para todas as parcelas no decorrer do estudo. Uma espécie,

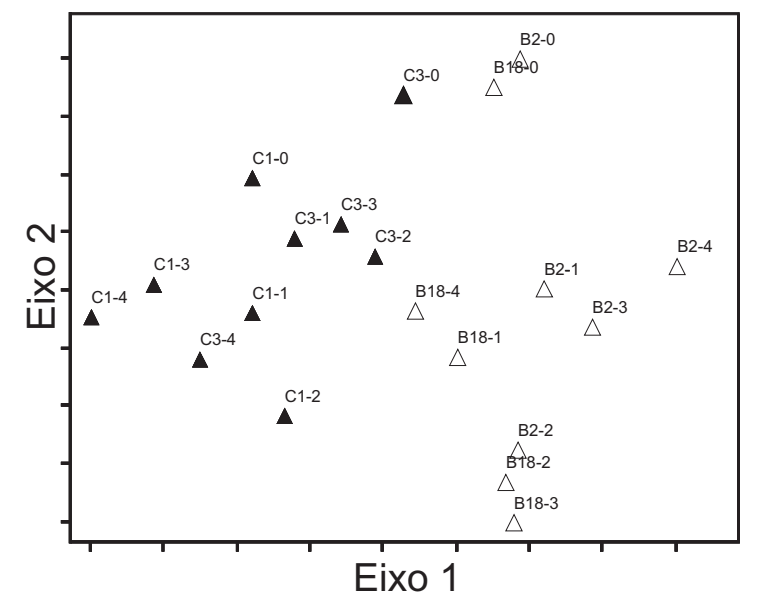

Figura 3 - Análise de correspondência retificada (DCA - Detrended Correspondence Analysis) de amostras de aves de sub-bosque em parcelas em floresta controle (triângulos preenchidos) e em floresta manejada (triângulos vazados) ao longo de 5 anos de amostragem na FLONA Tapajós, Brasil. Zero representa o período de pré-exploração. 
Tabela 1 - Número de indivíduos (com ordem de abundância) para as 33 espécies mais freqüentemente capturadas em uma amostra de 128 indivíduos em B18, 181 indivíduos em B2, 242 indivíduos em C1, 180 em C3 e 1048 indivíduos na amostra combinada em uma floresta de terra firme na FLONA Tapajós, Brasil, antes da exploração madeireira.

\begin{tabular}{|c|c|c|c|c|c|c|c|c|}
\hline \multirow[b]{2}{*}{ Espécie } & \multirow[b]{2}{*}{${ }^{1}$ Guilda } & \multicolumn{3}{|c|}{ Parcelas-Tratamento } & \multicolumn{3}{|c|}{ Parcelas-Controle } & \multirow[b]{2}{*}{ Total } \\
\hline & & B18 & B2 & B18 \& B2 & C1 & C3 & C1 \& C3 & \\
\hline Glyphorynchus spirurus & IBM & $22(1)$ & $37(1)$ & $59(1)$ & $29(1)$ & $25(1)$ & $54(1)$ & $113(1)$ \\
\hline Hylophylax poecilinotus & SFC & $10(2)$ & $12(3)$ & $22(2)$ & $8(6)$ & $17(2)$ & $25(3)$ & $47(2)$ \\
\hline Dendrocincla merula** & SFC & $6(5)$ & $2(21)$ & $8(11)$ & $20(3)$ & $12(3)$ & $32(2)$ & $40(3)$ \\
\hline Thamnomanes caesius & IBM & $6(5)$ & $16(2)$ & $22(2)$ & $6(11)$ & $11(4)$ & $17(5)$ & $39(4)$ \\
\hline Pipra rubrocapilla** & $\mathrm{F}$ & $4(11)$ & $4(11)$ & $8(11)$ & $21(2)$ & $2(21)$ & $23(4)$ & $31(5)$ \\
\hline Hylophylax naevius & IA & $6(5)$ & $8(4)$ & $14(4)$ & $4(18)$ & $8(6)$ & $12(11)$ & $26(6)$ \\
\hline Rhegmatorhina gymnops & SFC & $3(14)$ & $8(4)$ & $11(5)$ & $5(13)$ & $10(5)$ & $15(6)$ & $26(6)$ \\
\hline Phlegopsis nigromaculata & SFC & $3(14)$ & $7(6)$ & $10(8)$ & $5(13)$ & $8(6)$ & $13(8)$ & $23(8)$ \\
\hline Conopophaga aurita & IT & $5(8)$ & $6(9)$ & $11(5)$ & $5(13)$ & $5(8)$ & $10(13)$ & $21(9)$ \\
\hline Mionectes macconnelli** & $\mathrm{I} / \mathrm{F}$ & $4(11)$ & $2(21)$ & $6(15)$ & $12(4)$ & $3(16)$ & $15(6)$ & $21(9)$ \\
\hline Lepidothrix iris & $\mathrm{F}$ & $3(14)$ & $4(11)$ & $7(13)$ & $8(6)$ & $5(8)$ & $13(8)$ & $20(11)$ \\
\hline Myrmotherula Iongipennis & IBM & $4(11)$ & $7(6)$ & $11(5)$ & $4(18)$ & $3(16)$ & $7(16)$ & $18(12)$ \\
\hline Cyphorhinus arada* & $\mathrm{IT}$ & $8(3)$ & $2(21)$ & $10(8)$ & $7(8)$ & 0 & $7(16)$ & $17(13)$ \\
\hline Myrmotherula leucophthalma* & IBM & 0 & $7(6)$ & $7(13)$ & $7(8)$ & $3(16)$ & $10(13)$ & $17(13)$ \\
\hline Automolus infuscatus* & IBM & $2(18)$ & $1(27)$ & $3(25)$ & $7(8)$ & $5(8)$ & $12(11)$ & $15(15)$ \\
\hline Xenops minutus & IBM & $7(4)$ & $2(21)$ & $9(10)$ & $2(27)$ & $2(21)$ & $4(24)$ & $13(16)$ \\
\hline Platyrinchus coronatus ** & $\mathrm{IA}$ & 0 & 0 & 0 & $11(5)$ & $2(21)$ & $13(8)$ & $13(16)$ \\
\hline Thamnophilus schistaceus & IBM & $5(8)$ & $3(17)$ & $8(11)$ & $1(42)$ & $3(16)$ & $4(24)$ & $12(18)$ \\
\hline Myiobius barbatus & IBM & $5(8)$ & $1(27)$ & $6(15)$ & $5(13)$ & $1(31)$ & $6(19)$ & $12(18)$ \\
\hline Schiffornis turdina & $F / I$ & 0 & $4(11)$ & $4(20)$ & $3(22)$ & $5(8)$ & $8(15)$ & $12(18)$ \\
\hline Myrmoborus myotherinus & IA & $1(23)$ & $5(10)$ & $6(15)$ & $4(18)$ & $1(31)$ & $5(21)$ & $11(21)$ \\
\hline Dendrocincla fuliginosa & SFC & $3(14)$ & $1(27)$ & $4(20)$ & $2(27)$ & $4(12)$ & $6(19)$ & $10(22)$ \\
\hline Platyrinchus platyrhynchos & $\mathrm{IA}$ & $1(23)$ & $4(11)$ & $5(18)$ & $2(27)$ & $2(21)$ & $4(24)$ & $9(23)$ \\
\hline Cyanocompsa cyanoides* & $F / I$ & 0 & $1(27)$ & $1(36)$ & $6(11)$ & $1(31)$ & $7(16)$ & $8(24)$ \\
\hline Thamnophilus aethiops & IBM & $2(18)$ & $3(17)$ & $5(18)$ & $2(27)$ & 0 & $2(38)$ & $7(25)$ \\
\hline Onychorhynchus coronatus & IA & $1(23)$ & $3(17)$ & $4(20)$ & $2(27)$ & $1(31)$ & $3(31)$ & $7(25)$ \\
\hline Hylexetastes uniformis & SFC & $2(18)$ & $1(27)$ & $3(25)$ & 0 & $4(12)$ & $4(24)$ & $7(25)$ \\
\hline Turdus albicollis & $\mathrm{F} / \mathrm{I}$ & $1(23)$ & $1(27)$ & $2(30)$ & $3(22)$ & $2(21)$ & $5(21)$ & $7(25)$ \\
\hline Malacoptila rufa & IA & $2(18)$ & $1(27)$ & $3(25)$ & $2(27)$ & $1(31)$ & $3(31)$ & $6(29)$ \\
\hline Phoenicircus carnifex & $\mathrm{F} / \mathrm{I}$ & 0 & $2(21)$ & $2(30)$ & 0 & $4(12)$ & $4(24)$ & $6(29)$ \\
\hline Attila spadiceus* & IA & 0 & $4(11)$ & $4(20)$ & 0 & $1(31)$ & $1(57)$ & $5(31)$ \\
\hline Lanio versicolor* & IBM & 0 & $1(27)$ & $1(36)$ & $4(18)$ & 0 & $4(24)$ & $5(31)$ \\
\hline Percnostola leucostigma** & IA & 0 & 0 & 0 & $5(13)$ & 0 & $5(21)$ & $5(31)$ \\
\hline
\end{tabular}

1 Guildas: SFC = seguidores de formigas; $F=$ frugívoros; $I B M=$ insetívoros seguidores de bandos mistos; $I A=$ insetívoros arborícolas; $F / I=$ frugívoros-insetívoros solitários; IT = insetívoros terrícolas ;

${ }^{*} \mathrm{P}<0.05 \mathrm{e}^{* * \mathrm{P}}<0.01$

Automolus rufipileatus, foi registrada em $\mathrm{C} 1$ somente através de rede de neblina e em B2 foi registrada através de observação visual. As outras sete espécies ocorreram somente nas parcelas da floresta controle, sendo que quatro espécies, Corythopis torquatus, Hylophylax punctulatus, Percnostola leucostigma e Phaeothlypis rivularis, são espécies associadas a igarapés de floresta de terra firme, e duas, os piprídeos Manacus manacus e Chiroxiphia pareola, são espécies comuns em floresta secundária.
Considerando as 33 espécies mais comuns no período de pré-exploração nas quatro parcelas agrupadas, as quais apresentaram uma taxa de captura superior a $1 \mathrm{em} 1000 \mathrm{HR}$ (equivalente a 5 ou mais indivíduos), as únicas espécies registradas somente nas parcelas da floresta controle foram Platyrinchus coronatus e Percnostola leucostigma. Além destas espécies, mais nove espécies apresentaram um significativo desvio no número de indivíduos capturados nas parcelas controle em relação ao observado nas parcelas manejadas, 
considerando uma distribuição com proporções esperadas iguais (Tabela 1). Mesmo assim, as taxas de captura das 33 espécies mais comuns nas parcelas da floresta controle também não foram significativamente distintas das parcelas localizadas em floresta manejada antes da exploração (Teste de KruskalWallis, $H=5.51, g l=3, P=0.138)$. Novamente, tomando-se as parcelas duas a duas, a parcela B18 foi estatisticamente distinta da parcela C1 (Teste de Kruskal-Wallis, $H=6.43$, $g l=1, P=0.01$ ).

\section{PÓS-EXPLORAÇÃOO}

Nos quatro anos após a exploração foram capturados 1779 indivíduos de 108 espécies nas duas parcelas da floresta manejada. Isto representa uma taxa de captura de 137.27 indivíduos/1000HR. Apesar da taxa de captura ter sido um pouco inferior à observada no período de pré-exploração, não houve diferenças significativas relacionadas ao manejo $(P=0.195)$, tempo $(P=0.762)$ e nem uma interação entre manejo $v s$. tempo $(P=0.981)$. Não houve diferenças nas taxas de captura entre o período de pré-exploração e nenhum dos períodos de pós-exploração (Teste de Wilcoxon, $g l=1, P>0.05$, para todos os períodos considerados), indicando que a taxa de captura não foi significativamente alterada ao longo do tempo nas parcelas manejadas. Das 33 espécies consideradas comuns antes da exploração (taxa de captura acima de 1), 28 permaneceram comuns no período de pós-exploração (Tabela 2). Cinco espécies que eram comuns antes da exploração se tornaram raras e 10 espécies que eram raras se tornaram comuns. Apesar da taxa de captura para todas as 43 , ou seja, as 38 comuns e as cinco espécies que se tornaram incomuns, ter declinado de 130.56 indivíduos/1000HR no período de pré-exploração, para 105.56 indivíduos/1000HR ao final do estudo, a diferença observada não foi estatisticamente significativa (Teste de Wilcoxon, $g l=1, P>0.05$, para todos os períodos considerados). Contudo, a ordem das abundâncias apresentou um significativo efeito relacionado ao manejo (Kolmogorov-Smirnov, $g l=2 ; P<0.05$ para as amostras do tempo 0 vs. tempo 3, tempo $2 v$ s. tempo 4 e tempo $3 v$ s. tempo 4).

\section{EFEITOS DO MANEJO FLORESTAL E DO TEMPO NAS ESPÉCIES E GUILDAS DE AVES}

O manejo florestal teve efeito significativo sobre a taxa de captura de 21 espécies, enquanto outras 3 espécies tiveram suas taxas de captura afetadas pela interação entre manejo e tempo (Tabela 3). Destas espécies afetadas pela exploração madeireira, 8 foram mais abundantes na área manejada enquanto 160 foram na área controle. As taxas de captura de outras 9 espécies apresentaram um significativo efeito relacionado ao tempo.

INSETÍVOROS - As aves insetívoras apresentaram uma tendência decrescente, mas não significativa, nas taxas de captura tanto nas parcelas em floresta manejada como nas parcelas em floresta controle (Figura 4, Teste de Wilcoxon, $P>0.05$, para todos os períodos considerados).

INSETÍVOROS SEGUIDORES DE FORMIGAS DE CORREIÇÃO - Das nove espécies de insetívoros seguidores de formigas de correição apenas Dendrocincla merula e Dendrocolaptes picumnus apresentaram um significativo efeito relacionado ao manejo (Tabela 3; Figura 5). Capturas de $D$. merula foram mais comuns na floresta controle do que na floresta manejada no período de pré-exploração e nos tempos 2 e 3 do período pós-exploração. D. picumnus apresentou um consistente pico na taxa de captura observada na área manejada logo após a exploração madeireira (cerca de 1.85 indivíduos/1000HR e equivalente a $2 / 3$ de todos os indivíduos capturados durante o estudo), resultando em uma significativa interação entre manejo $v$ s. tempo e em uma correlação com o tempo não significativa $(r=0.359, P=0.553)$.

INSETÍVOROS SEGUIDORES DE BANDOS MISTOS - Espécies que participam de bandos mistos de insetívoros apresentaram uma tendência decrescente na taxa de captura tanto na floresta manejada como na floresta controle (Figura 4). Esta tendência foi significante entre o período anterior a exploração e 4 anos após a exploração na área manejada (Teste de Wilcoxon, $Z=1.96, P=0.0495)$. O declínio na taxa de captura foi significativamente correlacionado com o tempo na floresta manejada $(r=-0.9, P=0.0374)$, mas não floresta controle $(r=-0.6, P=0.285)$. O manejo florestal afetou as taxas de captura de três espécies comuns. Automolus infuscatus foi mais abundante na floresta controle do que na floresta manejada antes da exploração madeireira e, apesar da tendência de declínio observada na floresta controle, permaneceu mais abundante nos três anos seguintes à exploração (Tabela 1, Figura 5). Thamnophilus aethiops foi mais abundante na floresta manejada do que na floresta controle tanto no período anterior a exploração como nos quatro anos seguintes (Figura 5). A abundância de Xiphorhynchus spixii aumentou na floresta controle após a exploração madeireira (Figura 5). Não se observou uma interação significativa entre manejo e tempo, ou seja, a magnitude da diferença permaneceu relativamente estável ao longo do período de amostragem.

INSETÍVOROS ARBORÍCOLAS SOLITÁRIOS - Capturas de insetívoros arborícolas solitários se mantiveram estáveis ao longo do período de estudo nas parcelas manejadas e uma pequena queda foi observada nas parcelas controle (Figura 4). Contudo, alguns membros da guilda apresentaram efeitos significativos relacionados ao manejo ou ao tempo. Por exemplo, Hylophylax naevius foi mais capturado no período anterior do que no período posterior à exploração, tanto na floresta controle como na floresta manejada (Tabela 3, Figura 6). A tendência de declínio da abundância foi significativamente correlacionada com o tempo somente na floresta manejada $(r=-0.9, \mathrm{P}=0.0374)$. O manejo florestal 
Tabela 2 - Número de indivíduos (com ordem de abundância) para as 38 espécies mais freqüentemente capturadas em uma amostra de 128 indivíduos em B18, 181 indivíduos em B2, 242 indivíduos em C1 e 180 e 1048 indivíduos na amostra combinada em uma floresta de terra firme na FLONA Tapajós, Brasil, após exploração madeireira.

\begin{tabular}{|c|c|c|c|c|c|c|c|c|}
\hline \multirow[b]{2}{*}{ Espécie } & \multirow[b]{2}{*}{${ }^{1}$ Guilda } & \multicolumn{3}{|c|}{ Parcelas-Tratamento } & \multicolumn{3}{|c|}{ Parcelas-Controle } & \multirow[b]{2}{*}{ Total } \\
\hline & & B18 & B2 & B18 \& B2 & C1 & C3 & C1 \& C3 & \\
\hline Glyphorynchus spirurus & IBM & $83(1)$ & $143(1)$ & $226(1)$ & $164(1)$ & $89(1)$ & $253(1)$ & $479(1)$ \\
\hline Pipra rubrocapilla & $\mathrm{F}$ & $70(2)$ & $80(2)$ & $150(2)$ & $91(2)$ & $49(5)$ & $140(2)$ & $290(2)$ \\
\hline Hylophylax poecilinotus & SFC & $52(3)$ & $57(4)$ & $109(3)$ & $51(5)$ & $61(3)$ & $112(4)$ & $221(3)$ \\
\hline Mionectes macconnelli & $\mathrm{l} / \mathrm{F}$ & $27(6)$ & $24(13)$ & $51(8)$ & $74(3)$ & $50(4)$ & $124(3)$ & $175(4)$ \\
\hline Dendrocincla merula & SFC & $14(13)$ & $50(5)$ & $64(7)$ & $44(6)$ & $62(2)$ & $106(5)$ & $170(5)$ \\
\hline Myrmotherula Iongipennis & IBM & $42(4)$ & $29(8)$ & $71(6)$ & 37 (9) & $49(5)$ & $86(6)$ & $157(6)$ \\
\hline Thamnomanes caesius & IBM & $30(5)$ & $50(5)$ & $80(5)$ & $41(7)$ & $28(8)$ & $69(8)$ & $149(7)$ \\
\hline Phlegopsis nigromaculata & SFC & $18(7)$ & $63(3)$ & $81(4)$ & $17(17)$ & $27(9)$ & $44(13)$ & $125(8)$ \\
\hline Lepidothrix iris & $\mathrm{F}$ & $17(8)$ & $22(14)$ & $39(11)$ & $53(4)$ & $25(11)$ & $78(7)$ & $117(9)$ \\
\hline Rhegmatorhina gymnops & SFC & $10(24)$ & $34(7)$ & $44(9)$ & $15(20)$ & $40(7)$ & $55(9)$ & $99(10)$ \\
\hline Myrmotherula leucophthalma & IBM & $12(19)$ & $20(15)$ & $32(16)$ & $28(11)$ & $26(10)$ & $54(10)$ & $86(11)$ \\
\hline Thamnophilus aethiops & IBM & $14(13)$ & $25(11)$ & $39(11)$ & $11(28)$ & $11(22)$ & $22(27)$ & $61(12)$ \\
\hline Thalurania furcata & $\mathrm{N}$ & $14(13)$ & $5(39)$ & $19(26)$ & $26(12)$ & $15(14)$ & $41(14)$ & $60(13)$ \\
\hline Dendrocincla fuliginosa & SFC & $14(13)$ & $17(17)$ & $31(18)$ & $16(18)$ & $10(23)$ & $26(21)$ & $57(14)$ \\
\hline Malacoptila rufa & IA & $13(18)$ & $17(17)$ & $30(19)$ & $13(24)$ & $14(18)$ & $27(20)$ & $57(14)$ \\
\hline Arremon taciturnus & $\mathrm{I} / \mathrm{F}$ & $17(8)$ & $27(10)$ & $44(9)$ & $10(32)$ & $1(65)$ & $11(40)$ & $55(16)$ \\
\hline Platyrinchus coronatus & IA & $1(66)$ & $3(52)$ & $4(58)$ & $36(10)$ & $15(14)$ & $51(11)$ & $55(16)$ \\
\hline Thamnophilus schistaceus & IBM & $15(11)$ & $20(15)$ & $35(14)$ & $10(32)$ & $10(23)$ & $20(30)$ & $55(16)$ \\
\hline Turdus albicollis & $\mathrm{F} / \mathrm{I}$ & $2(53)$ & $1(68)$ & $3(63)$ & $39(8)$ & $12(21)$ & $51(11)$ & $54(19)$ \\
\hline Xenops minutus & IBM & $12(19)$ & $12(24)$ & $24(22)$ & $21(13)$ & $7(31)$ & $28(19)$ & $52(20)$ \\
\hline Xiphorhynchus spixii & IBM & $9(26)$ & $6(34)$ & $15(30)$ & $13(24)$ & $23(12)$ & $36(15)$ & $51(21)$ \\
\hline Myrmoborus myotherinus & IA & $14(13)$ & $25(11)$ & $39(11)$ & $6(44)$ & $5(39)$ & $11(40)$ & $50(22)$ \\
\hline Automolus infuscatus & IBM & $3(43)$ & $12(24)$ & $15(30)$ & $19(15)$ & $14(18)$ & $33(17)$ & $48(23)$ \\
\hline Conopophaga aurita & IT & $6(28)$ & $16(20)$ & $22(24)$ & $9(34)$ & $15(14)$ & $24(23)$ & $46(24)$ \\
\hline Hypocnemis cantator & IA & $16(10)$ & $17(17)$ & $33(15)$ & $7(41)$ & $5(39)$ & $12(37)$ & $45(25)$ \\
\hline Myiobius barbatus & IBM & $3(43)$ & $7(32)$ & $10(36)$ & $16(18)$ & $18(13)$ & $34(16)$ & $44(26)$ \\
\hline Platyrinchus platyrhynchos & $\mathrm{IA}$ & $10(24)$ & $10(28)$ & $20(25)$ & $9(34)$ & $13(20)$ & $22(27)$ & $42(27)$ \\
\hline Schiffornis turdina & $\mathrm{F} / \mathrm{I}$ & $4(35)$ & $5(39)$ & $9(39)$ & $18(16)$ & $15(14)$ & $33(17)$ & $42(27)$ \\
\hline Cyphorhinus arada & IT & $11(22)$ & $15(21)$ & $26(21)$ & $6(44)$ & $9(26)$ & $15(33)$ & $41(29)$ \\
\hline Geotrygon montana & FT & $5(30)$ & $13(23)$ & $18(27)$ & $14(21)$ & $9(26)$ & $23(24)$ & $41(29)$ \\
\hline Myrmeciza hemimelaena & IA & $15(11)$ & $14(22)$ & $29(20)$ & $8(38)$ & 0 & $8(52)$ & $37(31)$ \\
\hline Hylophylax naevius & IA & $2(53)$ & $11(26)$ & $13(32)$ & $13(24)$ & $10(23)$ & $23(24)$ & $36(32)$ \\
\hline Phaethornis superciliosus & $\mathrm{N} / \mathrm{l}$ & $7(27)$ & $9(30)$ & $16(29)$ & $11(28)$ & $9(26)$ & $20(30)$ & $36(32)$ \\
\hline Cyanocompsa cyanoides & $\mathrm{F} / \mathrm{I}$ & $12(19)$ & $11(26)$ & $23(23)$ & $9(34)$ & $2(55)$ & $11(40)$ & $34(34)$ \\
\hline Pyriglena leuconota & SFC & $4(35)$ & $28(9)$ & $32(16)$ & $2(69)$ & 0 & $2(78)$ & $34(34)$ \\
\hline Myrmotherula axillaris & IBM & $4(35)$ & $4(45)$ & $8(42)$ & $21(13)$ & $4(42)$ & $25(22)$ & $33(36)$ \\
\hline Onychorhynchus coronatus & IA & $2(53)$ & $5(39)$ & $7(45)$ & $14(21)$ & $8(30)$ & $22(27)$ & $29(37)$ \\
\hline Phaethornis arthopyga & $\mathrm{N}$ & $4(35)$ & $5(39)$ & $9(39)$ & $12(27)$ & $4(42)$ & $16(32)$ & $25(38)$ \\
\hline
\end{tabular}

1 Guildas: $\mathrm{SFC}=$ seguidores de formigas; $\mathrm{F}=$ frugívoros; $\mathrm{IBM}=$ insetívoros seguidores de bandos mistos; $I \mathrm{~A}=$ insetívoros arborícolas; $\mathrm{IT}=$ insetívoros terrícolas ; F/I = frugivoros-insetívoros; $1 / \mathrm{F}=$ Insetívoros-frugivoros; $\mathrm{N}=$ nectarivoros 
Tabela 3 - Número de capturas das espécies que exibiram uma marcada diferença na taxa de captura observada em área manejada e controle na FLONA Tapajós, Brasil. Os efeitos do manejo foram acessados através de ANOVA, sendo $\mathrm{M}=$ manejo (controle vs. manejada) e $\mathrm{T}=$ tempo ( 5 anos entre setembro de 1997 e dezembro de 2001).

\begin{tabular}{|c|c|c|c|c|c|c|}
\hline & \multirow[b]{2}{*}{ Guilda ${ }^{1}$} & \multicolumn{2}{|c|}{ Número de Capturas } & \multicolumn{3}{|c|}{ Nível de Significância } \\
\hline & & Controle & Manejada & M & $\mathrm{T}$ & $\mathrm{M} \times \mathrm{T}$ \\
\hline \multicolumn{7}{|c|}{ Espécies mais comuns na área controle } \\
\hline Automolus infuscatus & IBM & 45 & 26 & 0.043 & & \\
\hline Corythopis torquatus & IT & 12 & 0 & 0.013 & & \\
\hline Conopophaga aurita & IT & 34 & 33 & & 0.010 & \\
\hline Deconychura stictolaema & IBM & 11 & 2 & 0.007 & & 0.015 \\
\hline Dendrocincla merula & SFC & 138 & 72 & 0.026 & & \\
\hline Geotrygon montana & FT & 25 & 18 & & 0.034 & \\
\hline Habia rubica & $\mathrm{F} / \mathrm{I}$ & 17 & 4 & 0.021 & & \\
\hline Hylophylax naevius & IA & 35 & 27 & & 0.004 & \\
\hline Mionectes macconnelli & $\mathrm{l} / \mathrm{F}$ & 139 & 57 & 0.001 & 0.022 & 0.028 \\
\hline Myrmotherula menetriesii & IBM & 8 & 7 & & 0.013 & 0.007 \\
\hline Phaethornis bourcieri & $\mathrm{N}$ & 17 & 3 & 0.013 & & \\
\hline Phaethornis aethopyga & $\mathrm{N}$ & 17 & 9 & & 0.034 & \\
\hline Lepidothrix iris & FA & 91 & 46 & 0.046 & & \\
\hline Platyrinchus coronatus & IA & 64 & 4 & 0.008 & & \\
\hline Schiffornis turdina & $\mathrm{F} / \mathrm{l}$ & 41 & 13 & 0.003 & & \\
\hline Sclerurus caudacutus & IT & 25 & 2 & 0.002 & & \\
\hline Sclerurus mexicanus & IT & 10 & 7 & & 0.022 & \\
\hline Tachyphonus surinamus & $\mathrm{F} / \mathrm{l}$ & 13 & 0 & 0.026 & & \\
\hline Thalurania furcata & $\mathrm{N}$ & 43 & 19 & 0.011 & 0.020 & \\
\hline Turdus albicollis & $\mathrm{F} / \mathrm{I}$ & 14 & 5 & 0.003 & & \\
\hline Xiphorhynchus spixii & IBM & 39 & 16 & 0.011 & & \\
\hline \multicolumn{7}{|c|}{ Espécies mais comuns na área manejada } \\
\hline Arremon taciturnus & $\mathrm{I} / \mathrm{F}$ & 11 & 44 & 0.013 & & \\
\hline Dendrocolaptes picumnus & SFC & 1 & 11 & 0.012 & & 0.017 \\
\hline Formicarius analis & IT & 1 & 11 & 0.006 & & \\
\hline Malacoptila rufa & IA & 30 & 33 & & & 0.016 \\
\hline Mymeciza hemimelaena & IA & 10 & 30 & 0.007 & & \\
\hline Myrmoborus myotherinus & IA & 16 & 45 & 0.021 & & \\
\hline Sclerurus rufigularis & IT & 6 & 8 & & 0.001 & 0.012 \\
\hline Thamnophilus aethiops & IBM & 24 & 44 & 0.044 & & \\
\hline
\end{tabular}

1 Guildas: SFC = seguidores de formigas; FT = frugívoros terrícolas; FA= Frugívoros arborícolas; IBM= insetívoros seguidores de bandos mistos; IA= insetívoros arborícolas; $\mathrm{IT}=$ insetívoros terrícolas $; \mathrm{F} / \mathrm{I}=$ frugívoros-insetívoros; $\mathrm{I} / \mathrm{F}=$ Insetívoros-frugívoros; $\mathrm{N}=$ nectarivoros

afetou as taxas de captura de quatro espécies de insetívoros arborícolas solitários. Entretanto, essas espécies exibiram respostas variadas: a taxa de captura de Malacoptila rufa foi afetada por uma interação entre o manejo florestal e o tempo (Tabela 3). O padrão observado é de alternância entre a floresta controle e a floresta manejada no maior número de capturas (Figura 6); as abundâncias de Myrmeciza hemimelaena e Myrmoborus myotherinus foram afetadas pelo manejo florestal, sendo que as taxas de captura destas espécies aumentaram na floresta manejada após a exploração madeireira (Tabela 3,
Figura 6). Platyrinchus coronatus foi mais comum na floresta controle do que na floresta manejada tanto no período anterior como no período posterior a exploração (Tabela 1, Tabela 3, Figura 6). Não se observou uma interação significativa entre o manejo e o tempo, ou seja, a magnitude da diferença permaneceu relativamente estável ao longo do período de amostragem.

INSETÍVOROS TERRÍCOLAS SOLITÁRIOS - Insetívoros terrícolas solitários mostraram um significativo efeito de tempo e uma interação significativa entre tempo e manejo 
(ANOVA manejo $v$ s. tempo $0-4, F$ (tempo) $=4.85, P=0.0196$ e $F$ (interação manejo $v$ s. tempo) $=4.86, P=0.0196)$. O padrão observado é de um declínio nas taxas de captura entre o período anterior a exploração tanto na floresta manejada como na floresta controle, apresentando uma correlação negativa com o tempo na floresta controle $(r=-1, P=0.000)$. Entre os tempos 3-4, há uma continuação na tendência de queda nas taxas de captura na floresta controle e um aumento na floresta manejada, para os mesmos níveis observados durante o período anterior à exploração madeireira (Figura 4). Três espécies contribuíram de forma significativa para esse padrão (Tabela 3): Conopophaga aurita (Figura 5), que apresentou uma significativa correlação negativa com o tempo na floresta controle $(r=-0.975, \mathrm{P}=0.0048)$, Sclerurus mexicanus (Figura 6) e Sclerurus rufigularis (Figura 6).

Três espécies apresentaram efeitos significativos relacionados ao manejo (parcelas controle $v$ s. parcelas manejadas). Corythopis torquatus foi capturado exclusivamente nas parcelas controle tanto antes como após a exploração madeireira (Tabela 3, Figura 5). Sclerurus caudacutus foi significativamente mais capturado nas parcelas controle (Figura 6), enquanto Formicarius analis foi significativamente mais capturado nas parcelas manejadas (Figura 6). Sclerurus mexicanus apresentou uma interação significativa entre manejo e tempo, que foi caracterizada por um aumento na taxa de captura na área manejada a partir do segundo ano após a exploração. Contudo a correlação com o tempo não foi significativa $(r=0.667, \mathrm{P}=0.219)$.

ONÍVOROS - Apresentaram um significativo efeito relacionado ao manejo (ANOVA manejo vs. tempo $0-4, F$ (manejo)=11.37, $P=0.0071)$. No nível das espécies foram observadas várias respostas (Tabela 3): Mionectes macconnelli, espécie que foi significativamente mais capturada em floresta controle no período anterior à exploração (Tabela 1), aumentou em abundância na floresta controle e declinou na floresta manejada (Figura 7); Arremon taciturnus, que era raro tanto na floresta controle como na floresta manejada, apresentou um aumento na taxa de captura observada na floresta manejada um ano após a exploração madeireira (Figura 7); Tachyphonus surinamus não foi registrado em redes de neblina na floresta manejada e apresentou um discreto aumento na floresta controle após a exploração madeireira, chegando a ter um pico de 2.8 indivíduos/1000HR no

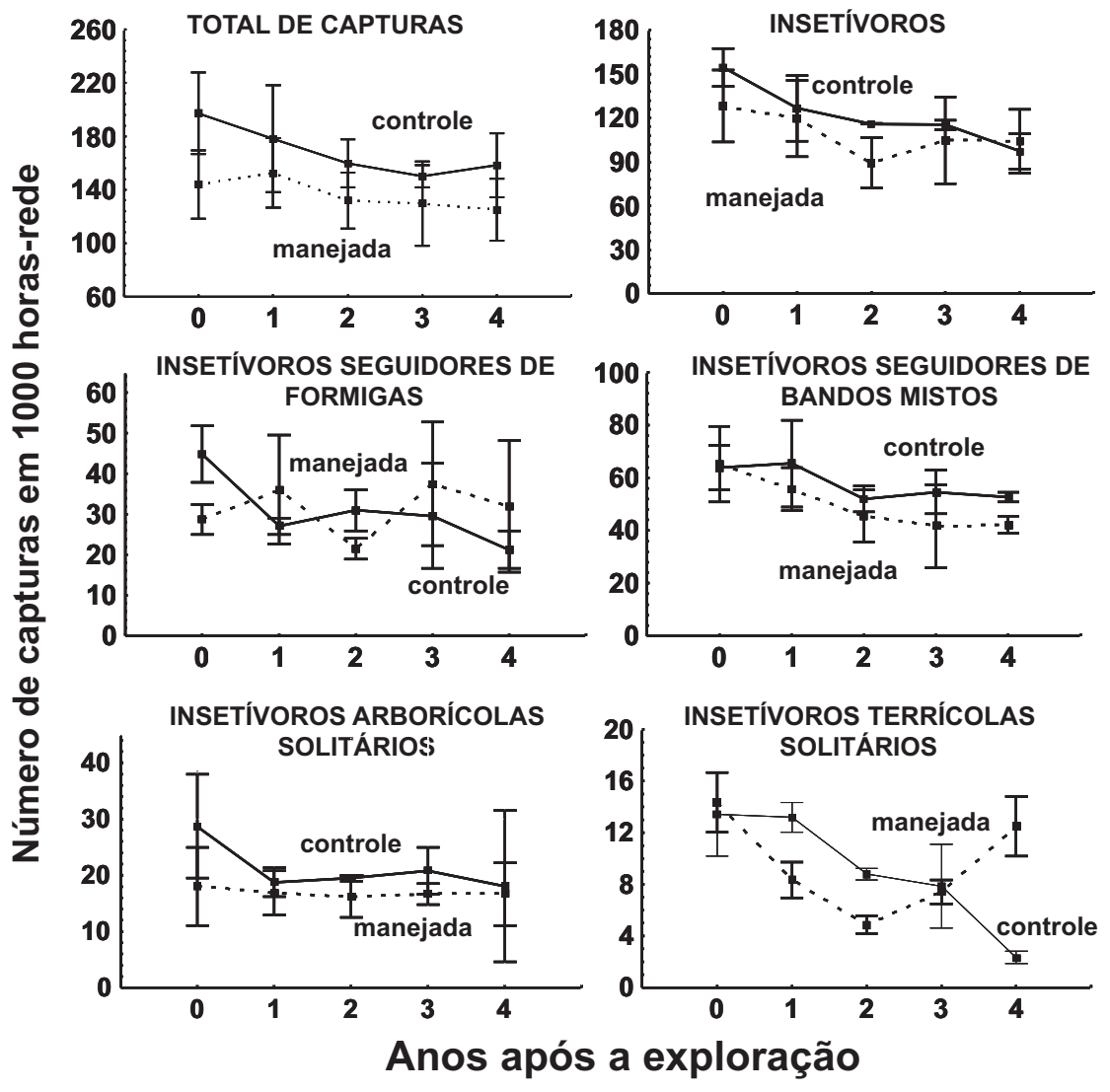

Figura 4 - Média e erro padrão para o número de capturas em 1000HR em floresta controle e floresta manejada para todas as capturas, todas as capturas de insetívoros e para as guildas dos seguidores de formigas, insetívoros seguidores de bandos mistos, insetívoros arborícolas solitários e insetívoros arborícolas terrícolas, como resultado de 5 anos de estudo na FLONA Tapajós. Zero representa o período de pré-exploração. 


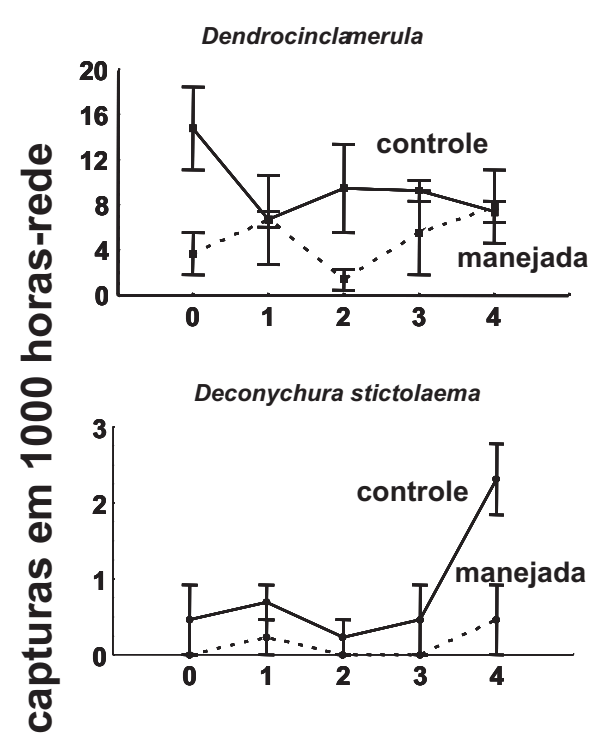

Xiphorhynchus spixii

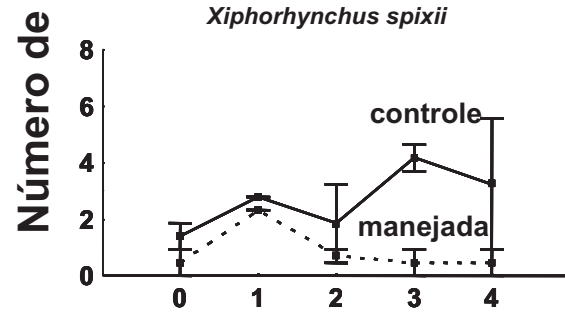

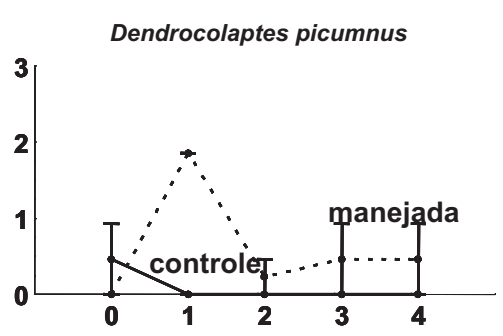

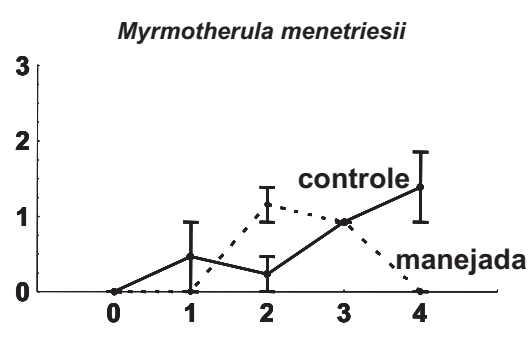

Corythopis torquata

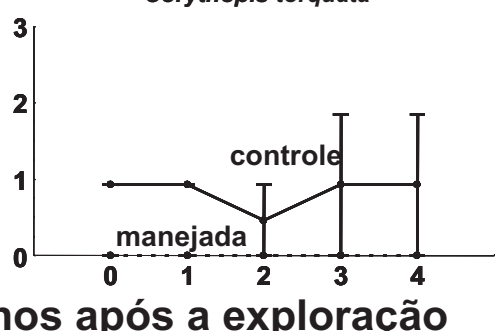

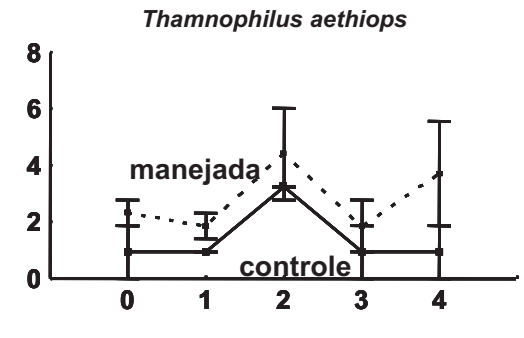

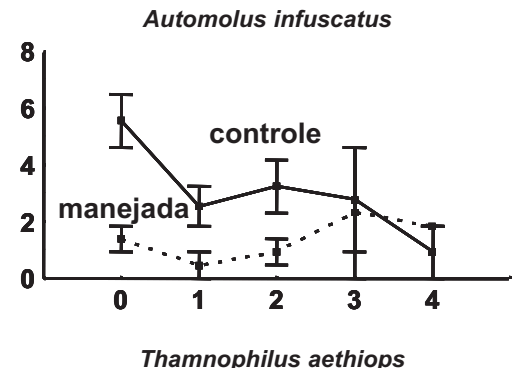

Conopophaga aurita

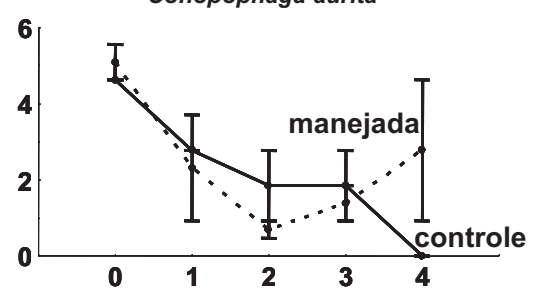

\section{Anos após a exploração}

Figura 5 - Média e erro padrão para o número de capturas em 1000HR em floresta controle e floresta manejada para as espécies Dendrocincla merula, Dendrocolaptes picumnus, Automolus infuscatus, Deconychura stictolaema, Myrmotherula menetriesii, Thamnophilus aethiops, Xiphorhynchus spixii, Corythopis torquatus e Conopophaga aurita como resultado de 5 anos de estudo na FLONA Tapajós. Zero representa o período de pré-exploração.

segundo ano após a exploração; Schiffornis turdina apresentou um declínio na floresta manejada e um aumento na floresta controle após a exploração madeireira (Figura 7); enquanto que Turdus albicollis foi consistentemente mais comum na floresta controle do que na floresta manejada, tanto no período pré-exploração como no período posterior à exploração madeireira (Figura 7).

FRUGÍVOROS - Houve pouca diferença na taxa de captura de aves frugívoras entre a floresta controle e a floresta manejada (Figura 8). Ao subdividir essa guilda em frugívoros arborícolas e frugívoros terrícolas também não são observados efeitos significativos relacionados ao manejo. Somente Lepidothrix iris foi consistentemente mais capturado na floresta controle do que na floresta manejada e a magnitude deste efeito foi estável ao longo do tempo (Tabela 3, Figura 8).

NECTARÍVOROS - Nectarívoros foram significativamente mais capturados na floresta controle do que na floresta manejada (ANOVA (manejo vs. tempo), $F($ manejo) $=10.582$, $P=0.008$, Figura 7). Este padrão foi em parte resultado das taxas de captura dos beija-flores Thalurania furcata e
Phaethornis bourcieri. O tempo também exerceu um efeito significativo sobre o número total de capturas de nectarívoros (ANOVA (manejo vs. tempo), $F($ tempo)=3.248, $P=0.0593$, Figura 8). A taxa de captura de nectarívoros aumentou ao longo do tempo na floresta manejada $(r=1, P=0.000)$. A maior parte deste padrão pode ser atribuída às capturas de Phaethornis aethopyga, cuja taxa de captura exibiu um efeito significativo relacionado ao tempo (Tabela 3, Figura 8) aumentando de forma consistente na floresta manejada ( $r=0.975, P=0.0048)$.

\section{DISCUSSÃO}

\section{EFEITOS NO NÍVEL DA COMUNIDADE}

Este estudo analisa pela primeira vez os efeitos decorrentes da exploração madeireira de baixo impacto com amostragens pré e pós-exploração, o que permite uma distinção mais acurada da variação da abundância das espécies e guildas relacionada com fatores ambientais locais. A hipótese de trabalho era que o manejo florestal de baixo impacto minimizasse os efeitos da exploração madeireira sobre a comunidade de aves. 

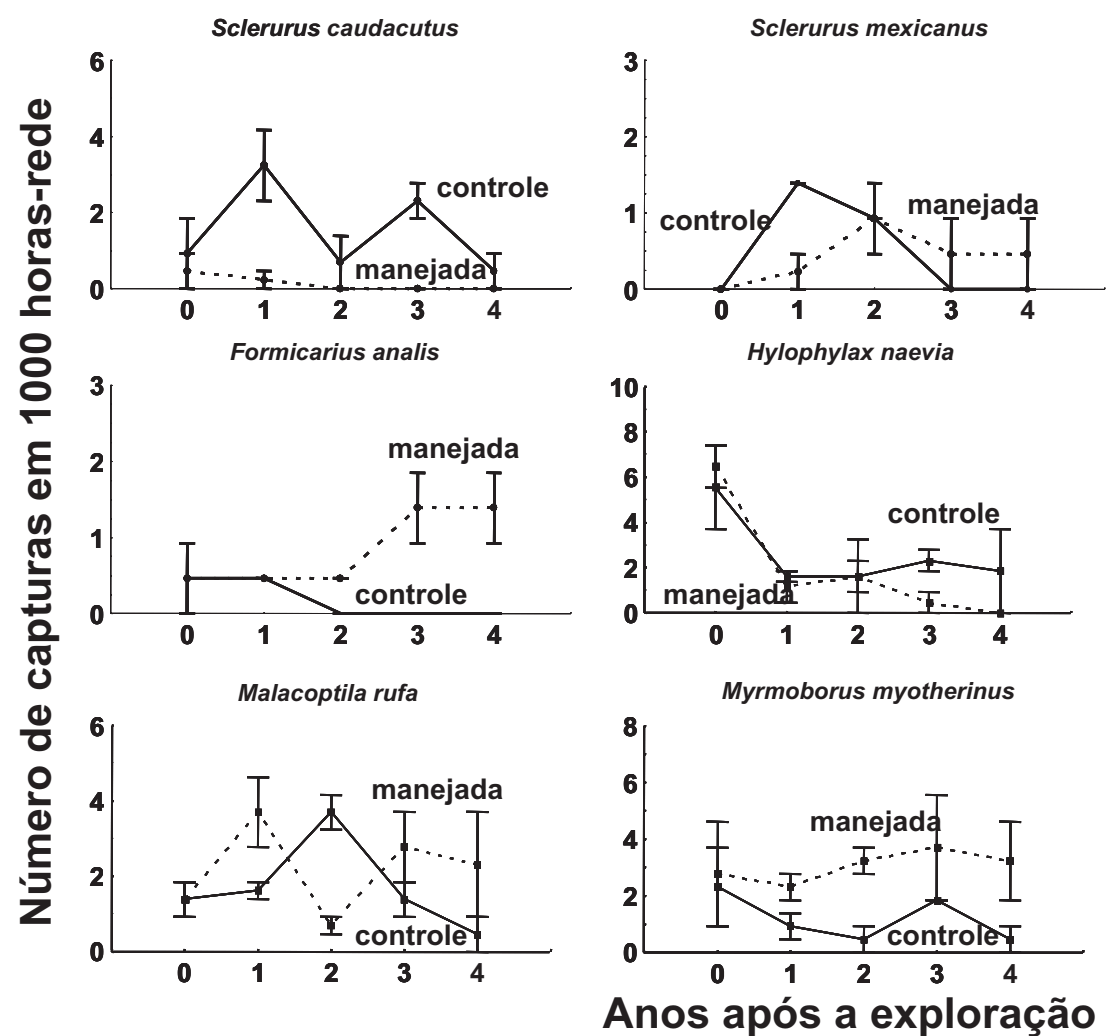
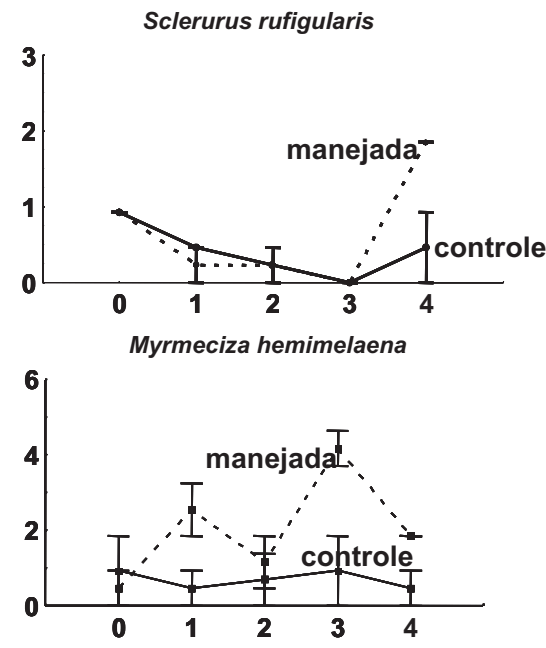

Platyrinchus coronatus

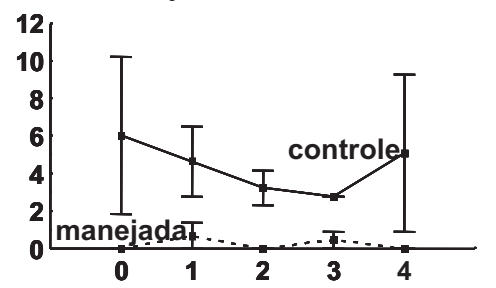

Figura 6 - Média e erro padrão para o número de capturas em 1000HR em floresta controle e floresta manejada para as espécies Sclerurus caudacutus, Sclerurus mexicanus, Sclerurus rufigularis, Formicarius analis, Hylophylax naevius Malacoptila rufa, Myrmeciza hemimelaena, Myrmoborus myotherinus e Platyrinchus coronatus, como resultado de 5 anos de estudo na FLONA Tapajós. Zero representa o período de pré-exploração.

Contudo, o procedimento de ordenação demonstrou que a similaridade entre as amostras diminuiu após a exploração madeireira em relação à similaridade observada entre as amostras do período de pré-exploração. Isto indica que apesar das diferenças existentes na composição da comunidade e na abundância de algumas espécies entre as parcelas localizadas em floresta controle e em floresta manejada no período anterior a exploração, essas diferenças foram aprofundadas em decorrência da exploração madeireira. Os efeitos do manejo florestal no nível da comunidade também são reforçados pela observação de que, apesar da taxa de captura total não ter declinado de maneira significativa, a ordem das abundâncias das 43 espécies mais comuns foi significativamente alterada entre o período anterior à exploração e 3 a 4 anos após a exploração. Os resultados também sugerem que os estudos comparativos entre sítios controle e sítios manejados baseados somente em amostragens do período posterior a exploração podem superestimar os efeitos da exploração madeireira. Isto é indicado pela observação de que três espécies (Automolus infuscatus, Dendrocincla merula e Platyrinchus coronatus) das 24 que apresentaram efeitos significativos relacionados ao manejo (parcelas controle $v$ s. parcelas manejadas) já apresentavam diferenças significativas na abundância no período anterior à exploração e que parte das espécies exclusivas da floresta controle, como por exemplo Corythopis torquatus, é uma espécie associada a igarapés de floresta de terra firme, um hábitat não encontrado na floresta manejada. Portanto, pelo menos $17 \%$ das espécies já apresentava uma diferença natural entre as abundâncias detectadas nas áreas controle versus a das áreas manejadas. Dessa maneira, o manejo florestal afetou de forma significativa a abundância de cerca de $15 \%$ das espécies de aves capturadas em redes na FLONA Tapajós. Outros estudos têm demonstrado que entre 14\% (Johns, 1996) e 61\% (Thiollay, 1992) da avifauna identificada em uma área podem ser significativamente afetadas pela exploração madeireira. O grande impacto observado por Thiollay (1992) pode em parte estar relacionado ao sítio em floresta não perturbada estar localizado a $130 \mathrm{~km}$ sudeste do sítio explorado, além do fato do autor ter amostrado somente as 

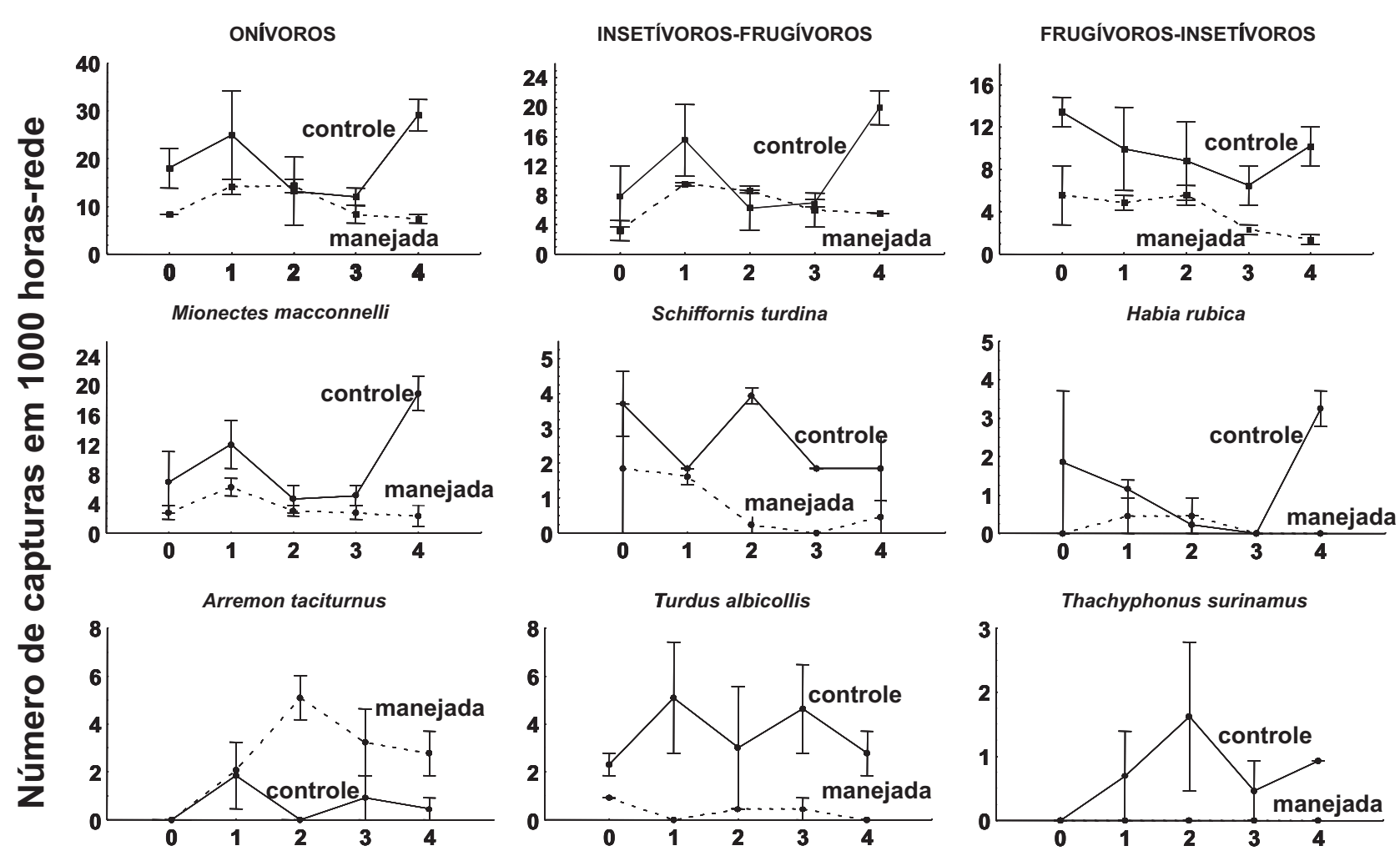

\section{Anos após a exploração}

Figura 7 - Média e erro padrão para o número de capturas em 1000HR em floresta controle e floresta manejada para todos os insetívoros/frugívoros, frugívoros/ insetívoros e para as espécies Mionectes macconnelli, Arremon taciturnus, Schiffornis turdina e Turdus albicollis como resultado de 5 anos de estudo na FLONA Tapajós. Zero representa o período de pré-exploração.

áreas abertas pela exploração, onde os danos à vegetação são mais severos, como sugerido por outros autores (Whitman et al., 1998). A estimativa de volume de madeira explorada nos sítios investigados por Thiollay (1992) foi de cerca de $11 \mathrm{~m}^{3 /}$ há, cerca de $40 \%$ inferior ao explorado na FLONA Tapajós. Isto sugere que o manejo florestal de baixo impacto minimizou os efeitos da exploração madeireira.

A ocorrência de uma diferença anterior à exploração madeireira na abundância de algumas espécies entre as florestas manejada e controle devido fatores ambientais locais (por exemplo, topografia, proximidade de igarapé, presença de vegetação secundária) reforça a idéia de que o melhor desenho experimental para avaliar os efeitos da exploração madeireira sob a comunidade de aves é um estudo longitudinal começando na floresta não explorada, e acompanhando os mesmos sítios ao longo do processo de regeneração. Portanto, o pressuposto de que diferenças nas abundâncias e na composição da comunidade de aves de uma área explorada e de uma área não perturbada são somente relacionadas à exploração madeireira pode ser incorreto, mesmo para sítios de amostragem relativamente próximos.

\section{EFEITOS DO MANEJO FLORESTAL E DO TEMPO NAS ESPÉCIES E} GUILDAS DE AVES

Mesmo considerando que quatro espécies, das 24 que apresentaram diferenças significativas nas abundâncias observadas na floresta manejada vs. floresta controle, já apresentavam essas diferenças no período anterior à exploração madeireira, os resultados corroboram algumas conclusôes de outros estudos com aves, nos quais os insetívoros, especialmente as espécies terrícolas e os insetívoros seguidores de bandos mistos, são as guildas mais negativamente afetadas pela exploração madeireira (Mason \& Thiollay, 2001). Ambas as guildas apresentaram uma tendência decrescente nas taxas de captura significativamente correlacionada com o tempo. Espécies que foram consistentemente mais comuns na floresta controle do que na floresta manejada incluíram três espécies especialistas em seguir bandos mistos (Deconychura stictolaema, Myrmotherula menetriesii e Xiphorhynchus spixii), e uma espécie de insetívoro terrícola ( $S$. caudacutus).

As aves seguidoras profissionais de formigas de correição, guilda indicada como altamente vulnerável às perturbações 

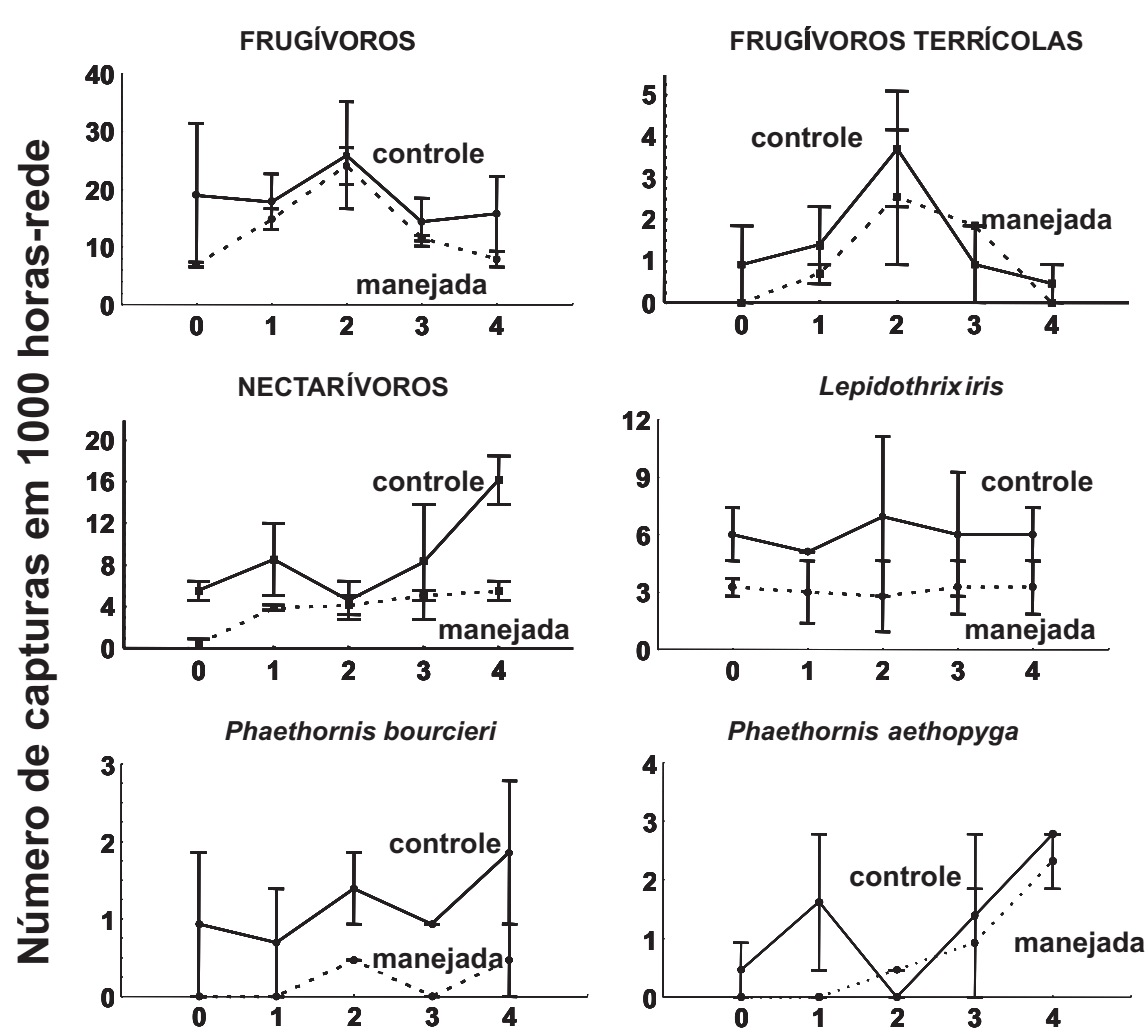

Anos após a exploração

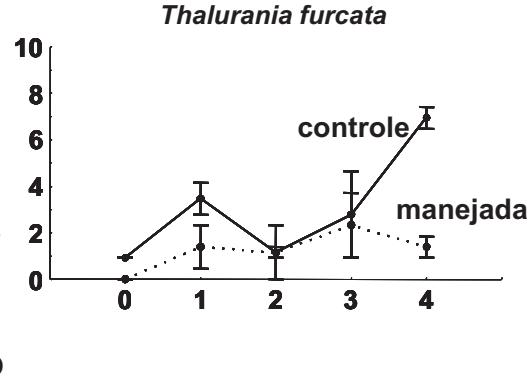

FRUGÍVOROS ARBORÍCOLAS
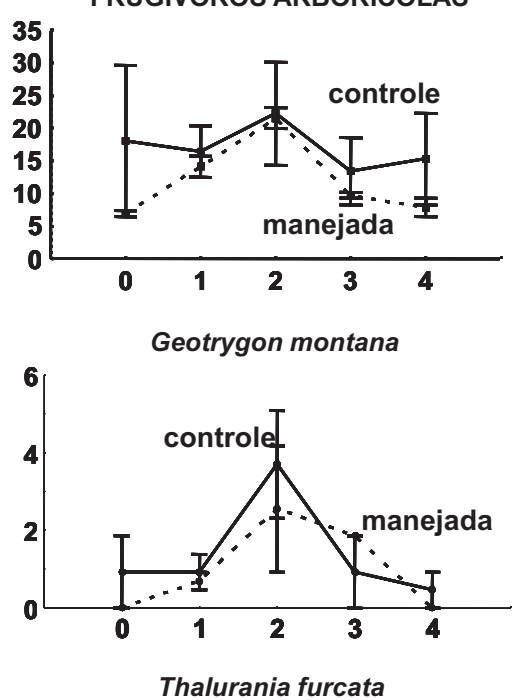

Figura 8 - Média e erro padrão para o número de capturas em 1000HR em floresta controle e floresta manejada para todos os frugívoros, frugívoros arborícolas, frugivoros terrícolas, nectarívoros e para as espécies Lepidothrix iris e Thalurania furcata como resultado de 5 anos de estudo na FLONA Tapajós. Zero representa o período de pré-exploração.

decorrentes da exploração madeireira em florestas na Guiana (Thiollay, 1992), da fragmentação florestal na Amazônia Central (Stouffer \& Bierregaard, 1995a) e do fogo (Barlow et al., 2002), não foram negativamente afetadas na FLONA Tapajós, com a possível exceção de Dendrocincla merula, uma espécie especialista em sub-bosque (Wunderle et al., 2005). Este resultado também foi observado na Venezuela por Mason (1996), que sugeriu dois fatores como possíveis razões para essa discrepância: Thiollay (1992) amostrou somente as áreas mais severamente perturbadas pela exploração madeireira (clareiras criadas pelo corte de árvores e ramais abertos pelo trator florestal), não amostrando as áreas que permanecem relativamente intactas após a exploração. Estas áreas podem representar importantes refúgios para as espécies que são altamente sensíveis à exploração (Lambert, 1992); e espécies tais como os seguidores profissionais de formigas são difíceis de observar fora das correiçóes de formigas (Bierregaard \& Lovejoy, 1989), sendo mais fáceis de detectar através de redes de neblina do que através de censo por ponto, método utilizado por Thiollay (1992). Outra possível razão é que no nível de guilda ocorreu uma compensação em que espécies especialistas em clareira aumentaram na floresta manejada, como por exemplo, Phlegopsis nigromaculata. Contudo, este estudo foi desenvolvido nos primeiros anos após a exploração. Em florestas na Guiana, a comunidade de aves de sub-bosque estava mais empobrecida após 10-12 anos do que nos dois primeiros anos após a exploração (Thiollay, 1992). Portanto, é esperado que declínios na abundância de outras espécies de aves de sub-bosque possam ser detectados em prazos mais longos, como também tem sido demonstrado por estudos sobre efeitos da fragmentação florestal em períodos de tempo relativamente longos (e.g. Stouffer \& Bierregaard, 1995a, 1995b, Ferraz et al., 2003). Esta conclusão é reforçada pela observação de que Hylophylax naevius também foi negativamente afetada pela exploração madeireira, pois apresentou um significativo declínio na abundância negativamente correlacionado com o tempo na floresta manejada.

Apesar das abundâncias dos insetívoros serem em geral inferiores na floresta manejada que na floresta controle, sete espécies afetadas pela exploração madeireira foram mais abundantes na floresta manejada do que na floresta controle: 
Malacoptila rufa, um insetívoro arborícola de biologia pouco conhecida, apresentou um padrão no qual a dominância de capturas variou entre a floresta controle e a floresta manejada em diferentes sessões de captura. Este padrão sugere que essa espécie utiliza recursos que favorecem deslocamentos espaciais amplos; Dendrocolaptes picumnus apresentou um pico na abundância observada na área manejada logo após a exploração madeireira e, em seguida, declinou para os mesmos níveis observados durante a fase de pré-exploração. Esta espécie é característica do médio-bosque e esse pico pode ser interpretado como um deslocamento vertical em resposta a perturbação do hábitat. Portanto, o padrão é consistente com os estudos que demonstram que o declínio dos insetívoros pode começar a ocorrer após vários anos desde a exploração. Em contraste, Formicarius analis e Sclerurus rufigularis apresentaram um aumento de abundância entre o terceiro e o quarto ano na floresta manejada e um continuado declínio na floresta controle. Estes resultados sugerem que a exploração madeireira de cerca de $40 \mathrm{~m}^{3} /$ ha que ocorreu em parcelas adjacentes a floresta controle no período deste experimento pode ter em algum grau afetado a abundância desses insetívoros terrícolas e, conseqüentemente, os efeitos negativos da exploração madeireira em escala comercial podem se estender para além das áreas exploradas; Myrmeciza hemimelaena e Myrmoborus myotherinus apresentaram um aumento consistente na floresta manejada. A primeira é um especialista em clareira (ver Wunderle et al., 2005) e a segunda é comum em floresta secundária. Isto sugere que florestas exploradas podem ser atrativas para algumas espécies de insetívoros que exploram recursos em áreas em regeneração. Contudo, quatro espécies especialistas em clareira (Myrmotherula menetriesii, Lepidothrix iris, Tachyphonus surinamus e Thalurania furcata) foram mais freqüentes na floresta controle do que na floresta manejada, o que sugere que as clareiras abertas pela exploração madeireira não mimetizam clareiras naturais. Este padrão também foi observado nas florestas da Guiana, em que um aumento da abundância foi observado somente para $23 \%$ das espécies associadas às clareiras (Thiollay, 1992).

Frugívoros tendem a ser mais resilientes aos efeitos da exploração madeireira do que insetívoros (Johns, 1988; Lambert, 1992; Thiollay, 1992; Mason, 1996; Guilherme \& Cintra, 2001; Mason \& Thiollay, 2001). Eles são adaptados para forragear sobre recursos que estão amplamente distribuídos, muitas vezes de maneira disjunta, e que são freqüentemente disponíveis durante um tempo limitado (Feinsinger, 1976; Levey, 1988). Portanto, essas espécies são relativamente mais hábeis em explorar os ambientes criados pela exploração madeireira (Johns, 1987; Mason, 1996). Uma única espécie de frugívoro foi consistentemente mais capturada na floresta controle do que na floresta manejada: Lepidothrix iris. A magnitude da diferença não foi significativamente alterada entre o período anterior e o período posterior à exploração madeireira e, por isso, não é possível concluir sobre os efeitos da exploração madeireira sobre essa espécie. Contudo, este resultado surpreende pelo fato dessa espécie ser um especialista em clareira (Wunderle et al., 2005).

Espécies onívoras não têm sido indicadas como negativamente afetadas pela exploração madeireira, e vários estudos têm demonstrado que algumas incrementam em abundância (Johns, 1996; Mason, 1996). Contudo, apesar de algumas exceçōes (e.g. Arremon taciturnus), insetívorosfrugívoros e frugívoros-insetívoros foram mais abundantes na floresta controle do que na floresta manejada. Além disso, insetívoros-frugívoros apresentaram um significativo aumento na floresta controle, padrão amplamente relacionado às capturas de Mionectes macconnelli na floresta controle. Este efeito, relacionado ao tempo, pode ter sido ocasionado por deslocamento a partir das parcelas adjacentes à floresta controle. Outros estudos em floresta amazônica têm documentado deslocamento de aves para dentro de fragmentos florestais após o desmatamento das florestas do entorno (Bierregaard \& Lovejoy, 1989; Bierregaard, 1990a). A presença de aves deslocadas pela exploração madeireira pode aumentar a competição por recursos nas reservas de floresta intacta. Portanto, o padrão apresentado por esta espécie também reforça a hipótese de que os efeitos da exploração madeireira em escala comercial $\left(40 \mathrm{~m}^{3} / \mathrm{ha}\right)$ podem se estender para além das áreas exploradas.

Nectarívoros têm sido apontados como o grupo mais favorecido pela exploração madeireira, pelo menos durante o período em que as plantas de sub-bosque estão respondendo ao aumento dos níveis de luz. Este padrão tem sido observado na Amazônia Central (Johns, 1991; Guilherme \& Cintra, 2001), Guiana (Thiollay, 1992; 1997) e Venezuela (Mason, 1996) e foi confirmado na FLONA Tapajós, onde o número de capturas de nectarívoros aumentou na floresta manejada. Este aumento foi associado em sua maior parte ao aumento das capturas de beija-flores de sub-bosque e não como resultado do deslocamento de espécies de dossel até o sub-bosque (i.e., Heliothryx auritus, Hylocharis sapphirina, Florisuga mellivora). Por exemplo, o número de capturas de Phaethornis aethopyga, um especialista em clareira, aumentou ao longo do tempo na floresta manejada, como demonstrado pela correlação positiva entre o tempo e a abundância na floresta manejada. Duas espécies, Phaethornis bourcieri e Thalurania furcata, apresentaram um efeito significativo relacionado ao manejo. O padrão apresentado pela primeira sugere que as abundâncias permaneceram relativamente estáveis entre o período anterior e o período posterior à exploração e que as diferenças nas abundâncias observadas na floresta controle e na floresta manejada já estavam presentes na comunidade. Em contraste, a segunda apresentou um significativo aumento na floresta controle após o terceiro ano desde a exploração. Portanto, o 
aumento na abundância de nectarívoros não foi confinado à floresta manejada. $\mathrm{O}$ aumento da abundância na floresta controle pode ter sido ocasionada por um deslocamento das áreas próximas que foram exploradas durante este estudo. A hipótese de deslocamento de beija-flores das parcelas manejadas em escala comercial, as quais foram exploradas com uma intensidade de $40 \mathrm{~m}^{3} / \mathrm{ha}$, para a floresta controle sugere que beija-flores de sub-bosque podem não ser tão resilientes à exploração madeireira quanto tem sido sugerido caso a intensidade de corte seja alta.

\section{IMPLICAÇÕES PARA MANEJO FLORESTAL}

Este estudo confirma que alteraçóes em grau variado podem ser detectadas na abundância das espécies de aves ao longo de um considerável período de tempo, mas não a ponto de impedir que estas espécies persistam nas florestas manejadas para exploração madeireira. Portanto, o manejo florestal de baixo impacto pode contribuir para que a maior parte da biodiversidade seja mantida ao longo de grandes áreas economicamente ativas. Contudo, considerando que os estudos têm demonstrado que as mudanças na composição da comunidade são proporcionais à magnitude da perturbação causada pelo manejo florestal, é recomendável que, além da utilização de todas as estratégias propostas para reduzir os danos associados à exploração madeireira, o volume de madeira que será autorizado explorar nessas florestas seja reavaliado. Neste estudo, o volume de madeira explorada foi cerca de metade do autorizado pelo Instituto Brasileiro de Meio Ambiente e Recursos Naturais Renováveis (IBAMA), órgão responsável pela administração das Florestas Nacionais e pela condução do processo de licenciamento de exploração nessas unidades de conservação. Mesmo assim, os efeitos detectados ainda são consistentes com o corpo de evidências de que comunidades animais são negativamente afetadas pela exploração madeireira. Além disso, mesmo que esta hipótese ainda não tenha sido diretamente testada, a exploração de parcelas adjacentes à floresta controle utilizando a intensidade das exploraçōes comerciais praticadas fora da FLONA Tapajós teve reflexos negativos sobre a abundância de algumas espécies e guildas na floresta controle.

$\mathrm{Na}$ Amazônia, o planejamento das áreas que são manejadas com finalidade de exploração madeireira não tem levado em conta consideraçôes ecológicas. Isso resulta em áreas testemunha localizadas em áreas declivosas, ou ainda, em solos pobres, ou com a presença de igarapés, o que não necessariamente representam as melhores escolhas para a finalidade de conservar uma área que sirva de testemunha do manejo florestal e dos tratamentos silviculturais. Na FLONA Tapajós essa realidade não foi diferente. A área escolhida para permanecer como testemunha da exploração madeireira, e utilizada como floresta controle neste estudo, ficou localizada ao longo do único curso dágua em uma considerável extensão da FLONA Tapajós. A área testemunha deve obrigatoriamente ser representativa das áreas exploradas. Não é recomendável deixar como testemunha somente as áreas impróprias para exploração, ou de exploração dificultada pela topografia e, portanto, mais caras, ou somente as áreas que obrigatoriamente devem ser mantidas como áreas protegidas de qualquer intervenção, como por exemplo, as áreas próximas aos cursos dágua.

Outras atividades humanas podem causar efeitos sinérgicos aos da exploração madeireira. A abertura das estradas que permitem a exploração madeireira também torna essas áreas acessíveis para caçadores, resultando em um maior impacto de caça (Robinson et al., 1999; Mason \& Thiollay, 2001). Em áreas onde a exploração ocorre de forma manejada e controlada, talvez este efeito indireto seja mais danoso às populações animais do que os efeitos diretos da exploração madeireira (Robinson et al., 1999). A abertura do dossel resseca as folhas e galhos do chão da floresta, aumentando o risco de fogo nas florestas exploradas (Uhl \& Vieira, 1988; Uhl \& Buschbacher, 1985; Uhl \& Kauffman, 1990). Na Amazônia, o fogo é amplamente utilizado na agricultura e na implantação de pastagens, tornando a ignição antropogênica perigosamente comum. Portanto, é essencial que as áreas exploradas sejam cuidadosamente manejadas para prevenir fogo e caça.

Exploração madeireira nas florestas nacionais é de grande interesse para a iniciativa privada assim como a replicação de uma prática de manejo sustentável é de grande interesse para a política ambiental. Documentação dos efeitos dessas práticas sobre a vida silvestre é necessária para o completo entendimento dos efeitos do manejo florestal. Portanto, a continuação do monitoramento tanto das parcelas exploradas experimentalmente como das parcelas exploradas pela iniciativa privada é necessário para revelar, em prazos ainda mais longos dos que os desenvolvidos nesse estudo, os efeitos da exploração madeireira.

\section{AGRADECIMENTOS}

Somos gratos aos assistentes de campo Laércio Damasceno Cabral, Gilson de Jesus Oliveira, Rosimar Pantoja Oliveira, moradores do entorno da Floresta Nacional do Tapajós, e Dionísio Corrêa Pimentel Neto, técnico taxidermista. Luiz Nélio Palheta e Sidnei de Melo Dantas também nos ajudaram no trabalho de campo. Cooperação e apoio logístico no campo foram concedidos pelo Instituto Brasileiro de Meio Ambiente e Recursos Naturais Renováveis (IBAMA) e pelo Large-Scale Biosphere Atmosphere Ecology Project (LBA). Fundos foram concedidos pelo Museu Paraense Emílio Goeldi (MPEG), Conselho Nacional de Desenvolvimento Científico e Tecnológico (CNPq), Fundo Estadual de Ciência Tecnologia 
do Estado do Pará (FUNTEC), Fundação O Boticário (FBPN) e USDA Forest Service.

\section{BIBLIOGRAFIA CITADA}

Aleixo, A. 1997. Effects of selective logging on a bird community in the Brazilian Atlantic forest. Condor, 101: 537-548.

Barreto, P.; Amaral, P.; Vidal, E.; Uhl, C. 1998. Costs and benefits of forest management for timber production in eastern Amazonia. Forest Ecology and Management, 108: 9-26

Barlow, J.; Haugaasen, T.; Peres, C. A. 2002. Effects of ground fires on understorey bird assemblages in Amazonian forests. Biological Conservation, 105: 157-169.

Barros, P.L.C.; Jardim, F.C. S. 1996. Plano de manejo florestal da Floresta Nacional do Tapajós, Pará, Brasil. IBAMA / PNUD

Bierregaard, R.O., Jr.; Lovejoy, T.E. 1989. Effects of forest fragmentation on Amazonian understory bird communities. Acta Amazonica, 19: 215-241.

Bierregaard, R.O., Jr. 1990a. Species composition and trophic organization of the understory bird community in a central Amazonian terra firme forest. Pp. 161-181 in A. H. Gentry (Ed.). Four Neotropical rainforests. Yale University Press, New Haven, Connecticut, USA.

Bierregaard, R.O., Jr. 1990b. Avian communities in the understory of Amazonian forest fragments. Pp. 333-343 in A. Keast (Ed.). Biogeography and ecology of forest bird communities. Academic Publishing, The Hague, The Netherlands.

Chazdon, R.L. 1998. Tropical forest - log 'em or leave 'em? Science 281: 1295-1296.

Comitê Brasileiro de Registros Ornitológicos. 2007. Listas das aves do Brasil. Versão 16/8/2007. Disponível em <http://www.cbro. org.br>. Acesso em: 13/08/2007.

Feinsinger, P. 1976. Organization of a tropical guild of nectarivorous birds. Ecological Monographs, 46: 257-291.

Ferraz, G.; Russell, G.J.; Stouffer, P.C.; Bierregaard, R.O.; Pimm, S.L.; Lovejoy, T.E. 2003. Rates of species loss from Amazonian forest fragments. Proceedings of the National Academy of Sciences of the United States of America, 100(24): 14069-14073.

Frumhoff, P.C. 1995 Conserving wildlife in tropical forests managed for timber. Bioscience, 34: 456-464.

Guilherme, E.; Cintra, R. 2001. Effects of intensity and age of selective logging and tree girdling on an understorey bird community composition in central Amazonia, Brazil. Ecotropica, 7: 77-92.

Hartshorn, G.S. 1989 Application of gap theory to tropical forest management: natural regeneration on strip clear-cuts in the Peruvian Amazon. Ecology, 70: 567-569

Henriques, L.M.P.; Wunderle, J.M.Jr.; Willig, M.R. 2003. Birds of the Tapajós National Forest, Brazilian Amazon: A preliminary assessment. Ornitologia Neotropical, 14: 307-338.

INPE. 1996. Deforestation in Braziliam Amazonia 1992-1994. Instituto de Pesquisas Espaciais/MCT.

INPE. 1998. Deforestation in Braziliam Amazonia 1995-1997. Instituto de Pesquisas Espaciais/MCT.
Johns, A.D. 1987. The use of primary forest and selectively logged rain forest by Malaysian Hornbills (Bucerotidae) and implications for their conservation. Biological Conservation, 40: 179-190.

Johns, A.D. 1988. Effects of "selective" timber extraction on rain forest structure and composition an some consequences for frugivores and folivores. Biotropica, 20: 31-37.

Johns, A.D. 1991. Responses of Amazonian rain forest birds to habitat modification. Journal of Tropical Ecology, 7: 417-437.

Johns, A.G. 1996. Bird population persistence in Sabahan logging concessions. Biological Conservation, 75: 3-10.

Johns, J.S.; Barreto, P.; Uhl, C. 1996. Logging damage in planned and unplanned logging operations in eastern Amazon. Forest Ecology and Management, 89: 59-77.

Karr, J.R. 1981. Surveying birds with mist nets. Studies in Avian Biology, 6: 62-67.

Karr, J.R. 1982. Avian extinction on Barro Colorado Island, Panama: a reassessment. American Naturalist, 119: 220-239.

Lambert, F.R. 1992. The consequences of selective logging for Bornean lowland forest birds. Philosophical Transactions of the Royal Society of London Series B, 335: 443-457.

Laurance, W.F. 1998. A crisis in the making: responses of Amazonian forest to land use and climate change. Trends in Evolution and Ecology, 13: 411-414.

Lentini, M.; Veríssimo, A.; Sobral, L. 2003. Fatos florestais da Amazônia. IMAZON, Belém.

Levey, D.J. 1988. Spatial and temporal variation in Costa Rican fruit and fruit-eating bird abundance. Ecological Monographs, 58: 251-269.

Mason, D. 1996. Responses of Venezuelan understory birds to selective logging, enrichment strips, and vine cutting. Biotropica, 28: 296-309.

Mason, D.; Thiollay, J.M. 2001. Tropical forestry and the conservation of Neotropical birds. Pp. 167-191 In: R.A. Fimbel, A. Grajal \& J.G. Robinson (Eds.). The cutting edge: conserving wildlife in logged tropical forests. Columbia University Press, New York, New York, USA.

Parrotta, J.A.; Francis, J.K.; Almeida, R.R. 1995. Trees of the Tapajós - a photographic field guide. Gen. Tech. Rep. IITF-1, Rio Piedras, PR: U. S. Department of Agriculture, Forest Service, International Institute of Tropical Forestry. 370pp.

Remsen, J.V. Jr.; Good, D.A. 1996. Misuse of data from mistnet captures to assess relative abundance in bird populations. $A u k$, 113: 381-398.

Remsen, J.V.; Parker, T.A. III. 1983. Contribution of river-created habitats to bird species richness in Amazonian. Biotropica, 15: 223-231

Robinson, J.G.; Redford, K.H.; Bennett, E. 1999. Wildlife harvest in logged tropical forest. Science, 284: 595-596.

Stouffer, P.C.; Bierregaard, R.O.Jr. 1995a. Use of Amazonian forest fragments by understory insectivorous birds. Ecology, 76: 2429-2445. 
Stouffer, P.C.; Bierregaard, R.O.Jr. 1995b. Effects of forest fragmentation on understory hummingbirds in Amazonian Brazil. Conservation Biology, 9:1085-1094.

Stratford, J.A.; Stouffer, P.C. 1999. Local extinctions of terrestrial insectivorous birds in a fragmented landscape near Manaus, Brazil. Conservation Biology, 13: 1416-1423.

Thiollay, J.M. 1992. Influence of selective logging on bird species diversity in a Guianan rain forest. Conservation Biology, 6: 4763.

Thiollay, J.M. 1997. Disturbance, selective logging and bird diversity: a neotropical forest study. Biodiversidade and Conservation, 6: 1155-1173.

Uhl, C.; Kauffman, B.J. 1990. Deforestation, fire susceptibility, and potential tree responses to fire in the eastern of Amazon. Ecology, 71: 437-449.

Uhl, C.; Buschbacher, R. 1985. A disturbing synergism between cattle ranch burning practices and selective tree harvesting in the Eastern Amazon. Biotropica, 17: 265-268.

Uhl, C.; Vieira, I.C.G. 1989. Ecological impacts of selective logging in the Brazilian Amazon: a case study from the Paragominas Region of the State of Para. Biotropica, 21: 98-106.

Verissimo, A.; Cochrane, M.A.; Souza, C. 2002. National forests in the Amazon. Science, 297: 1478.
Veríssimo, A.; Cochrane, M.A.; Souza, C.Jr.; Salomão, R. 2002. Priority areas for establishing national forests in the Brazilian Amazon. Conservation Ecology, 6: 4.

Whitman, A.A.; Hagan, J. M.III; Brokaw, N. V. L. 1998. Effect of selective logging on birds of northern Belize. Biotropica, 30: 449-457.

Whitmore, T.C. 1997. Tropical forest disturbance, dissappearance, and species loss. Pp. 3-12 in W. F. Laurence \& R. O. Bierregaard (Eds.). Tropical Forest Remnants: Ecology, Management, and Conservation of Fragmented Communities. University of Chicago Press, Chicago.

Woltmann, S. 2003. Bird community response to disturbance in a forestry concession in lowland Bolivia. Biodiversity and Conservation, 12: 1921-1936.

Wong, M. (Ed.). 1985. Understory birds as indicators of regeneration in a patch of selectively logged West Malaysian rainforest. International Council for Bird Preservation, Cambridge, UK.

Wunderle, J.M.; Willig, M.R.; Henriques, L.M.P. 2005. Avian distribution in treefall gaps and understory of terra firme forest in the lowland Amazon. Íbis, 147: 109-129.

Recebido em 07/03/2006

Aceito em 14/02/2008 
APÊNDICE. Espécies de aves capturadas na floresta controle e na floresta manejada e suas taxas de captura em 1000HR antes e depois da exploração madeireira de baixo impacto na FLONA Tapajós, Brasil. A lista foi organizada de acordo com seqüência taxonômica do CRBO (Comitê Brasileiro de Registros Ornitológicos, 2007)

\begin{tabular}{|c|c|c|c|c|c|}
\hline \multirow[b]{2}{*}{ Famílias e Espécies } & \multicolumn{2}{|c|}{ Floresta Manejada } & \multicolumn{2}{|c|}{ Floresta Controle } & \multirow[b]{2}{*}{ Guilda* } \\
\hline & Pré-exploração & Pós-exploração & Pré-Exploração & Pós-Exploração & \\
\hline \multicolumn{6}{|l|}{ TINAMIDAE } \\
\hline Crypturellus variegatus & 0 & 0 & 0 & 0.058 & $\mathrm{~F}$ \\
\hline \multicolumn{6}{|l|}{ ACCIPTRIDAE } \\
\hline Leucopternis kuhli & 0 & 0.174 & 0 & 0.058 & $\mathrm{PVI}$ \\
\hline Morphus guianensis & 0 & 0 & 0 & 0.058 & $\mathrm{PVI}$ \\
\hline \multicolumn{6}{|l|}{ FALCONIDAE } \\
\hline Micrastur ruficollis & 0 & 0.116 & 0 & 0.231 & $\mathrm{PVI}$ \\
\hline Micrastur gilvicollis & 0 & 0.289 & 0 & 0.174 & $\mathrm{PVI}$ \\
\hline \multicolumn{6}{|l|}{ PSOPHIDAE } \\
\hline Psophia viridis & 0 & 0 & 0 & 0.058 & $\mathrm{Fl}$ \\
\hline \multicolumn{6}{|l|}{ COLUMBIDAE } \\
\hline Leptotila rufaxilla & 0 & 0 & 0 & 0.058 & $\mathrm{~F}$ \\
\hline Geotrygon montana & 0 & 1.273 & 0.926 & 1.505 & $\mathrm{~F}$ \\
\hline \multicolumn{6}{|l|}{ STRIGIDAE } \\
\hline Glaucidium hardyi & 0 & 0.116 & 0 & 0 & \\
\hline \multicolumn{6}{|l|}{ CAPRIMULGIDAE } \\
\hline Nyctiphrynus ocellatus & 0 & 0.116 & 0 & 0 & $\mathrm{IA}$ \\
\hline \multicolumn{6}{|l|}{ TROCHILIDAE } \\
\hline Glaucis hirsutus & 0 & 0 & 1.389 & 0.347 & $\mathrm{~N}$ \\
\hline Phaethornis rupurumii & 0 & 0,347 & 0 & 0,173611 & $\mathrm{~N}$ \\
\hline Phaethornis aethopyga & 0 & 0,926 & 0,463 & 1,447 & $\mathrm{~N}$ \\
\hline Phaethornis bourcieri & 0 & 0.231 & 0.926 & 1.215 & $\mathrm{~N}$ \\
\hline Phaethornis superciliosus & 0.463 & 1.273 & 0.926 & 1.620 & $\mathrm{~N}$ \\
\hline Campylopterus largipennis & 0 & 0 & 0.463 & 0.810 & $\mathrm{~N}$ \\
\hline Florissuga mellivora & 0 & 0.058 & 0 & 0 & $\mathrm{~N}$ \\
\hline Thalurania furcata & 0 & 1.565 & 0.926 & 3.588 & $\mathrm{~N}$ \\
\hline Hylocharis sapphirina & 0 & 0.174 & 0 & 0 & $\mathrm{~N}$ \\
\hline Heliothryx auritus & 0 & 0.116 & 0 & 0.116 & $\mathrm{~N}$ \\
\hline \multicolumn{6}{|l|}{ TROGONIDAE } \\
\hline Trogon rufus & 1.389 & 0.752 & 0.463 & 0.231 & IFBM \\
\hline \multicolumn{6}{|l|}{ ALCEDINIDAE } \\
\hline Chloroceryle aenea & 0 & 0.116 & 0 & 0.058 & $\mathrm{PVI}$ \\
\hline \multicolumn{6}{|l|}{ MOMOTIDAE } \\
\hline Baryphthengus ruficapillus & 0 & 0 & 0 & 0.058 & IF \\
\hline Momotus momota & 0 & 0 & 0 & 0.058 & IF \\
\hline \multicolumn{6}{|l|}{ GALBULIDAE } \\
\hline Galbula cyanicollis & 0 & 0.116 & 0.926 & 0.694 & $\mathrm{IA}$ \\
\hline Jacamerops aureus & 0 & 0.058 & 0 & 0 & IA \\
\hline \multicolumn{6}{|l|}{ BUCCONIDAE } \\
\hline Bucco capensis & 0 & 0.116 & 0.463 & 0.116 & IA \\
\hline Malacoptila rufa & 1.389 & 2.373 & 1.389 & 1.794 & IA \\
\hline Monasa morphoeus & 0 & 0.347 & 0 & 0.174 & IBM \\
\hline
\end{tabular}




\begin{tabular}{|c|c|c|c|c|c|}
\hline \multirow[b]{2}{*}{ Famílias e Espécies } & \multicolumn{2}{|c|}{ Floresta Manejada } & \multicolumn{2}{|c|}{ Floresta Controle } & \multirow[b]{2}{*}{ Guilda* } \\
\hline & Pré-exploração & Pós-exploração & Pré-Exploração & Pós-Exploração & \\
\hline \multicolumn{6}{|l|}{ RAMPHASTIDAE } \\
\hline Selenidera gouldii & 0.463 & 0 & 0 & 0 & $\mathrm{FI}$ \\
\hline \multicolumn{6}{|l|}{ PICIDAE } \\
\hline Picumnus aurifrons & 0 & 0 & 0.926 & 0 & IA \\
\hline Veniliornis affinis & 0.463 & 0 & 0 & 0.116 & IBM \\
\hline Celeus elegans & 0 & 0.058 & 0 & 0.116 & IF \\
\hline \multicolumn{6}{|l|}{ THAMNOPHILIDAE } \\
\hline Cymbilaimus lineatus & 0 & 0.579 & 0 & 0.174 & \\
\hline Thamnophilus aethiops & 2.315 & 2.951 & 0.926 & 1.505 & IBM \\
\hline Thamnophilus schistaceus & 3.704 & 2.431 & 1.852 & 1.447 & IBM \\
\hline Thamnomanes caesius & 10.185 & 5.556 & 7.870 & 4.919 & IBM \\
\hline Myrmotherula leucophthalma & 3.241 & 2.720 & 4.630 & 4.514 & IBM \\
\hline Myrmotherula ornata & 0 & 0.174 & 0.926 & 0.058 & IBM \\
\hline Myrmotherula hauxwelli & 1.852 & 0.116 & 0 & 0.694 & IBM \\
\hline Myrmotherula axillaris & 0.463 & 0.521 & 1.389 & 1.794 & IBM \\
\hline Myrmotherula Iongipennis & 5.093 & 5.440 & 3.241 & 6.887 & IBM \\
\hline Myrmotherula menetriesii & 0 & 0.521 & 0 & 0.752 & IBM \\
\hline Dichrozona cincta & 0.463 & 0.289 & 0 & 0.926 & IT \\
\hline Cercomacra cinerascens & 0 & 0.058 & 0 & 0 & IA \\
\hline Pyriglena leuconota & 0.463 & 2.604 & 0 & 0.116 & SFC \\
\hline Myrmoborus myotherinus & 2.778 & 3.125 & 2.315 & 0.926 & IA \\
\hline Hypocnemis cantator & 0.463 & 2.315 & 0.926 & 1.099 & IA \\
\hline Sclateria naevia & 0 & 0 & 0 & 0.810 & IA \\
\hline Schistocichla leucostigma & 0 & 0 & 2.315 & 0.116 & IA \\
\hline Myrmeciza hemimelaena & 0.463 & 2.431 & 0.926 & 0.636 & IA \\
\hline Myrmornis torquata & 0.463 & 0.926 & 0.463 & 0.636 & IT \\
\hline Rhegmatorhina gymnops & 5.093 & 3.472 & 6.944 & 3.993 & SFC \\
\hline Hylophylax naevius & 6.481 & 0.810 & 5.556 & 1.852 & IA \\
\hline Hylophylax punctulatus & 0 & 0 & 0.926 & 0.752 & IA \\
\hline Hylophylax poecilinotus & 10.185 & 8.507 & 11.574 & 8.854 & SFC \\
\hline Phlegopsis nigromaculata & 4.630 & 6.424 & 6.018 & 3.183 & SFC \\
\hline \multicolumn{6}{|l|}{ CONOPOPHAGIDAE } \\
\hline Conopophaga aurita & 5.092 & 1.793 .981 & 4.630 & 1.620 & IT \\
\hline \multicolumn{6}{|l|}{ GRALLARIIDAE } \\
\hline Hylopezus macularius & 0 & 0 & 0.463 & 0.174 & IT \\
\hline Myrmothera campanisona & 0 & 0.058 & 0 & 0.116 & IT \\
\hline \multicolumn{6}{|l|}{ FORMICARIIDAE } \\
\hline Formicarius colma & 0.926 & 0.174 & 0.463 & 0.058 & IT \\
\hline Formicarius analis & 0.463 & 0.926 & 0.463 & 0.116 & IT \\
\hline \multicolumn{6}{|l|}{ SCLERURIDAE } \\
\hline Sclerurus mexicanus & 0 & 0.521 & 0 & 0.579 & IT \\
\hline Sclerurus rufigularis & 0.926 & 0.579 & 0.926 & 0.289 & IT \\
\hline Sclerurus caudacutus & 0.463 & 0.058 & 0.926 & 1.678 & IT \\
\hline \multicolumn{6}{|l|}{ DENDROCOLAPTIDAE } \\
\hline Dendrocincla fuliginosa & 1.852 & 2.431 & 2.778 & 1.852 & IA \\
\hline Dendrocincla merula & 3.704 & 5.382 & 14.815 & 8.218 & SFC \\
\hline
\end{tabular}




\begin{tabular}{|c|c|c|c|c|c|}
\hline \multirow[b]{2}{*}{ Famílias e Espécies } & \multicolumn{2}{|c|}{ Floresta Manejada } & \multicolumn{2}{|c|}{ Floresta Controle } & \multirow[b]{2}{*}{ Guilda* } \\
\hline & Pré-exploração & Pós-exploração & Pré-Exploração & Pós-Exploração & \\
\hline Deconychura longicauda & 0 & 0.116 & 0 & 0.463 & IBM \\
\hline Deconychura stictolaema & 0 & 0.174 & 0.463 & 0.926 & IBM \\
\hline Glyphorynchus spirurus & 27.315 & 16.725 & 25 & 18.519 & IBM \\
\hline Hylexetastes uniformis & 1.389 & 0.926 & 1.852 & 0.579 & SFC \\
\hline Xiphocolaptes promeropirhynchus & 0.463 & 0.174 & 0 & 0.058 & IA \\
\hline Dendrocolaptes certhia & 1.389 & 1.273 & 0.463 & 0.463 & SFC \\
\hline Dendrocolaptes picumnus & 0 & 0.752 & 0.463 & 0 & SFC \\
\hline Xiphorhynchus spixii & 0.463 & 0.984 & 1.389 & 3.009 & IBM \\
\hline Xiphorhynchus guttatus & 0 & 0.521 & 0.463 & 0.289 & IBM \\
\hline Campylorhamphus procurvoides & 0 & 0.174 & 0 & 0.058 & IBM \\
\hline \multicolumn{6}{|l|}{ FURNARIIDAE } \\
\hline Philydor erythrocercum & 0 & 0.116 & 0 & 0.116 & IBM \\
\hline Philydor ruficaudatum & 0.463 & 0.463 & 0.926 & 0.868 & IBM \\
\hline Philydor pyrrhodes & 0 & 0.058 & 0.463 & 0.231 & IBM \\
\hline Automolus ochralaemus & 0 & 0.058 & 0 & 0.521 & IA \\
\hline Automolus infuscatus & 1.389 & 1.389 & 5.556 & 2.373 & IBM \\
\hline Automolus rufipileatus & 0 & 0 & 0.463 & 0.058 & IA \\
\hline Xenops minutus & 4.167 & 2.025 & 1.852 & 2.373 & IBM \\
\hline \multicolumn{6}{|l|}{ TYRANNIDAE } \\
\hline Mionectes oleagineus & 0.463 & 0.058 & 0 & 0.521 & IF \\
\hline Mionectes macconnelli & 2.778 & 3.588 & 6.944 & 10.185 & IF \\
\hline Corythopis torquatus & 0 & 0 & 0.926 & 0.810 & IT \\
\hline Lophotriccus galeatus & 0 & 0.636574 & 0 & 0 & IA \\
\hline Rhynchocyclus olivaceus & 0 & 0.174 & 0 & 0.289 & IA \\
\hline Tolmomyias sulphurescens & 0 & 0.116 & 0 & 0 & IA \\
\hline Platyrinchus saturatus & 0 & 0.289 & 0 & 0.694 & IA \\
\hline Platyrinchus coronatus & 0 & 0.289 & 6.018 & 3.935 & IA \\
\hline Platyrinchus platyrhynchos & 2.315 & 1.331 & 1.852 & 1.505 & IA \\
\hline Onychorhynchus coronatus & 1.852 & 0.521 & 1.389 & 1.736 & IA \\
\hline Myiobius barbatus & 2.778 & 0.636 & 2.778 & 2.720 & IBM \\
\hline Terenotriccus erythrurus & 0 & 0.463 & 0 & 0.289 & IA \\
\hline Rhytipterna simplex & 0 & 0.116 & 0.463 & 0 & IA \\
\hline Ramphotrigon ruficauda & 0 & 0.116 & 0 & 0.347 & IA \\
\hline Attila spadiceus & 1.852 & 0.810 & 0.463 & 0.579 & IA \\
\hline \multicolumn{6}{|l|}{ COTINGIDAE } \\
\hline Phoenicircus carnifex & 0.926 & 0.058 & 1.852 & 0.058 & $\mathrm{Fl}$ \\
\hline Lipaugus vociferans & 0 & 0.405 & 0 & 0.174 & $\mathrm{Fl}$ \\
\hline \multicolumn{6}{|l|}{ PIPRIDAE } \\
\hline Tyranneutes stolzmanni & 0 & 0.058 & 0 & 0 & IF \\
\hline Lepidothrix iris & 3.241 & 3.067 & 6.019 & 6.018 & FA \\
\hline Manacus manacus & 0 & 0 & 0.926 & 0.347 & FA \\
\hline Chiroxiphia pareola & 0 & 0 & 0.463 & 0.405 & FA \\
\hline Dixiphia pipra & 0 & 0.174 & 0 & 0.058 & FA \\
\hline Pipra rubrocapilla & 3.704 & 10.012 & 10.648 & 10.011 & FA \\
\hline \multicolumn{6}{|l|}{ TITYRIDAE } \\
\hline Schiffornis turdina & 1.852 & 0.579 & 3.704 & 2.373 & IF \\
\hline
\end{tabular}




\begin{tabular}{|c|c|c|c|c|c|}
\hline \multirow[b]{2}{*}{ Famílias e Espécies } & \multicolumn{2}{|c|}{ Floresta Manejada } & \multicolumn{2}{|c|}{ Floresta Controle } & \multirow[b]{2}{*}{ Guilda* } \\
\hline & Pré-exploração & Pós-exploração & Pré-Exploração & Pós-Exploração & \\
\hline Laniocera hypopyrrha & 0 & 0.174 & 0.926 & 0.347 & IF \\
\hline Pachyramphus marginatus & 0 & 0.116 & 0 & 0 & IF \\
\hline \multicolumn{6}{|l|}{ VIREONIDAE } \\
\hline Hylophilus hypoxanthus & 0 & 0 & 0 & 0.058 & IA \\
\hline Hylophilus ochraceiceps & 0.463 & 0.231 & 1.389 & 0.289 & IBM \\
\hline \multicolumn{6}{|l|}{ TROGLODITYDAE } \\
\hline Microcerculus marginatus & 0.926 & 0.752315 & 0.926 & 0.116 & IT \\
\hline Thryothorus coraya & 0 & 0.231 & 0.926 & 0.579 & IA \\
\hline Thryothorus leucotis & 0 & 0 & 0 & 0.058 & IA \\
\hline Cyphorhinus arada & 4.630 & 2.199 & 3.241 & 0.926 & IT \\
\hline \multicolumn{6}{|l|}{ POLIOPTILIDAE } \\
\hline Ramphocaenus melanurus & 0.463 & 0.347 & 0 & 0.174 & IBM \\
\hline \multicolumn{6}{|l|}{ TURDIDAE } \\
\hline Catharus fuscecens & 0 & 0.058 & 0 & 0 & IF \\
\hline Turdus albicollis & 0.926 & 0.231 & 2.314 .815 & 3.877 & $\mathrm{Fl}$ \\
\hline \multicolumn{6}{|l|}{ THRAUPIDAE } \\
\hline Habia rubica & 0 & 0.231 & 1.851 .852 & 1.157 & $\mathrm{FI}$ \\
\hline Tachyphonus cristatus & 0 & 0.058 & 0 & 0.058 & IFBM \\
\hline Tachyphonus surinamus & 0 & 0 & 0 & 0.926 & IFBM \\
\hline Lanio versicolor & 0.463 & 0.579 & 1.852 & 0.231 & IBM \\
\hline Ramphocelus carbo & 0 & 0.058 & 0 & 0.058 & $\mathrm{Fl}$ \\
\hline \multicolumn{6}{|l|}{ EMBERIZIDAE } \\
\hline Sporophila angolensis & 0 & 0.058 & 0 & 0 & $\mathrm{FI}$ \\
\hline Arremon taciturnus & 0 & 3.298 .611 & 0 & 0.810 & IF \\
\hline \multicolumn{6}{|l|}{ CARDINALIDAE } \\
\hline Periporphyrus erythromelas & 0 & 0.058 & 0 & 0 & FA \\
\hline Saltator grossus & 0.926 & 0.289 & 0.463 & 0.116 & $\mathrm{Fl}$ \\
\hline Saltator maximus & 0 & 0.058 & 0 & 0.058 & $\mathrm{Fl}$ \\
\hline Cyanocompsa cyanoides & 0.463 & 15.625 & 3.240 .741 & 0.868 & $\mathrm{Fl}$ \\
\hline \multicolumn{6}{|l|}{ PARULINAE } \\
\hline Phaeothlypis rivularis & 0 & 0 & 1.389 & 0.347 & IA \\
\hline Granatellus pelzelni & 0 & 0 & 0 & 0.116 & $\mathrm{FI}$ \\
\hline TOTAL & 143.982 & 134.607 & 196.759 & 161.400 & \\
\hline
\end{tabular}

*Guilda: $\mathrm{F}$ = frugívoro; $\mathrm{Fl}$ = frugívoro-insetívoro; IT = insetívoro terrícola; $\mathrm{IA}=$ insetívoro arborícola; $\mathrm{IBM}$ = insetívoro seguidor de bando misto; $\mathrm{SFC}=$ insetívoro seguidor de formiga de correição; IF = insetivoro-frugívoro; $\mathrm{N}$ = nectarivoro; $\mathrm{PVI}=$ pequenos vertebrados e insetos grandes 
